Supporting Information

\title{
Pathway Manipulation via Ni, Co, V Ternary Synergism to Realize High Efficiency of Urea Electrocatalytic Oxidation
}

Zhijiao Ji, ${ }^{a}$ Yajun Song, ${ }^{a}$ Shenghao Zhao, ${ }^{a}$ Yi Li, ${ }^{\text {acd }}{ }^{*}$ Jia Liu, ${ }^{a b *}$ Wenping Hu ${ }^{\text {acd }}$

a Zhijiao Ji, Yajun Song, Shenghao Zhao, Dr. Jia Liu, Prof. Yi Li, Prof. Wenping Hu Tianjin Key Laboratory of Molecular Optoelectronics, Department of Chemistry, School of Science, Tianjin University, Tianjin 300072, People's Republic of China

${ }^{b}$ Dr. Jia Liu

Key Laboratory of Advanced Energy Materials Chemistry (Ministry of Education), College of Chemistry, Nankai University, Tianjin 300071, People's Republic of China

c Prof. Wenping Hu, Prof. Yi Li

Collaborative Innovation Center of Chemical Science and Engineering (Tianjin), Tianjin 300072, People's Republic of China.

d Prof. Wenping Hu, Prof. Yi Li

Joint School of National University of Singapore and Tianjin University, Fuzhou International Campus, Tianjin University, Binhai New City, Fuzhou,350207, People's Republic of China.

*E-mail:

liujia@tju.edu.cn

liyi@tju.edu.cn 


\section{Methods}

\subsection{Chemicals and materials.}

All reagents were used without further purification. nickel nitrate hexahydrate $\left(\mathrm{Ni}\left(\mathrm{NO}_{3}\right)_{2} \cdot 6 \mathrm{H}_{2} \mathrm{O}\right)$, cobalt nitrate hexahydrate $\left(\mathrm{Co}\left(\mathrm{NO}_{3}\right)_{2} \cdot 6 \mathrm{H}_{2} \mathrm{O}\right)$, vanadium trichloride $\left(\mathrm{VCl}_{3}\right)$, trimesic acid (98\%), thioacetamide (TAA, 99\%), and urea (99\%) were purchased from Shanghai Aladdin Biochemical Technology Co. Ltd. Ethanol (99.5\%), N,N-dimethylformamide (99.9\%), isopropanol (99.9\%) and Polyvinylpyrrolidone (PVP, $M W=1300000$ ) were purchased from Saen Chemical Technology (Shanghai) Co. Ltd, Nafion 117 solution (5\%) was purchased from Sigma-Aldrich. Potassium hydroxide (KOH) was purchased from Tianjin Damao Chemical. Milli-Q ultrapure water (resistance of 18.2 $\mathrm{M} \Omega \cdot \mathrm{cm}^{-1}$ at $\left.25^{\circ} \mathrm{C}\right)$ was used for all experiments. Carbon paper $(1 \times 1.5 \mathrm{~cm})$ was used as a substrate for routine electrochemical testing and copper foil $(1.5 \times 1.5 \mathrm{~cm})$ was used as working electrode in the in-situ electrocatalytic Raman test.

\subsection{Preparation of Materials}

1.2.1. Synthesis of Ni-Co sulfide. The Ni-Co sulfide was prepared through a simple two-step hydrothermal method. The first step was to prepare the polymer complex precursor, and the second step was to prepare the sulfide. Firstly, $0.75 \mathrm{~g}$ PVP $(\mathrm{Mw}=1300000)$ was dispersed in $15 \mathrm{ml}$ solution $\left(\mathrm{V}_{\text {water }}: \mathrm{V}_{\text {ethanol }}: \mathrm{V}_{\mathrm{N}, \mathrm{N} \text {-dimethylformamide }}=1: 1: 1\right)$ and stirred vigorously for at least $3 \mathrm{~h}$. Subsequently, $218.107 \mathrm{mg}(0.75 \mathrm{mmol})$ of $\mathrm{Ni}\left(\mathrm{NO}_{3}\right)_{2} \cdot 6 \mathrm{H}_{2} \mathrm{O}$ and a certain amount of $\mathrm{Co}\left(\mathrm{NO}_{3}\right)_{2} \cdot 6 \mathrm{H}_{2} \mathrm{O}$ were added into the solution and stirred vigorously. Finally, trimellitic acid ligand was added and the molar ratio of ligand and metal was 1:2. After stir for $1 \mathrm{~h}$, the solution was transferred into a $25 \mathrm{~mL}$ PTFE-lined 
stainless steel autoclave. The sealed autoclave was heated to $150{ }^{\circ} \mathrm{C}$ and maintained for 10 h. After the reaction, the stainless steel autoclave cooled naturally, the product was washed with absolute ethanol 4 times, and dried under vacuum at $60{ }^{\circ} \mathrm{C}$ for $12 \mathrm{~h}$. The amount of $\mathrm{Co}\left(\mathrm{NO}_{3}\right)_{2} \cdot 6 \mathrm{H}_{2} \mathrm{O}$ was $54.57 \mathrm{mg}(0.187 \mathrm{mmol}), 36.38 \mathrm{mg}(0.125 \mathrm{mmol}), 27.36 \mathrm{mg}(0.094$ mmol), $21.83 \mathrm{mg}(0.075 \mathrm{mmol}), 14.55 \mathrm{mg}$ (0.05 mmol), $10.91 \mathrm{mg}(0.0375 \mathrm{mmol})$, respectively and these samples were named NC-BTC-1, NC-BTC-2, NC-BTC-3, NC-BT-4, NC-BTC-5, NC-BTC-6. A sample only containing Ni or Co element was used as a control group and named N-BTC or C-BTC.

To prepare metal sulfides, $20 \mathrm{mg}$ as-prepared complex precursor and $80 \mathrm{mg}$ thioacetamide were dispersed in $15 \mathrm{ml}$ isopropanol, after stirring for $1 \mathrm{~h}$ to form a uniform suspension, the solution was transferred to $25 \mathrm{ml}$ PTFE-lined stainless steel autoclave, the tightened reactor was placed in an oven at $180^{\circ} \mathrm{C}$ for $24 \mathrm{~h}$. After the reaction, the product was naturally cooled to room temperature, and washed with water and ethanol three times. Finally, it was dried under vacuum at $60{ }^{\circ} \mathrm{C}$ for $12 \mathrm{~h}$. In order to be consistent with the naming of the complex, we named the sulfides as NCS-1, NCS-2, NCS-3, NCS-4, NCS-5, NCS-6, NS and CS.

1.2.2 Synthesis of Ni-V sulfide. The preparation method of Ni-V sulfide was slightly different from that of Ni-Co sulfide. Firstly, $0.75 \mathrm{~g}$ PVP $(\mathrm{Mw}=1300000)$ and $218.107 \mathrm{mg}$ $(0.75 \mathrm{mmol}) \mathrm{Ni}\left(\mathrm{NO}_{3}\right)_{2} \cdot 6 \mathrm{H}_{2} \mathrm{O}$ were dissolved in $15 \mathrm{ml}$ solution $\left(\mathrm{V}_{\text {water }}: \mathrm{V}_{\text {ethanol }}: \mathrm{V}_{\mathrm{DMF}}=1: 1: 1\right)$ to get the solution A. Secondly, $66.36 \mathrm{mg}(0.422 \mathrm{mmol})$ of $\mathrm{VCl}_{3}$ was dispersed in $450 \mu \mathrm{L}$ of ultrapure water to get a concentrated solution B. After $40 \mu \mathrm{L}, 80 \mu \mathrm{L}, 120 \mu \mathrm{L}, 160 \mu \mathrm{L}$ of $\mathrm{B}$ was added to A respectively and stirred for $1 \mathrm{~h}$ to get the homogeneous solution, it was 
transferred to a $25 \mathrm{~mL}$ stainless steel reactor, the tightened reactor was kept in an oven at $150{ }^{\circ} \mathrm{C}$ for $10 \mathrm{~h}$. After the reaction, the produce was washed 4 times with absolute ethanol, and dried in vacuum at $60^{\circ} \mathrm{C}$ for $12 \mathrm{~h}$. Based on the amount of $\mathrm{V}$, the samples were named NV-BTC-1, NV- BTC-2, NV-BTC-3, NV-BTC-4. The method of preparing Ni-V sulfide was the same as that of Ni-Co sulfide. In order to be consistent with the naming of NiV-BTC, we named Ni-V sulfides as NVS-1, NVS-2, NVS-3, NVS-4. As a control, the vanadium sulfide (VS) was obtained through hydrothermal method using $\mathrm{VCl}_{3}(33.5 \mathrm{mg}$, $0.213 \mathrm{mmol})$ and TAA ( $80 \mathrm{mg}, 1.065 \mathrm{mmol})$ as raw material directly.

1.2.3 Synthesis of Ni-Co-V sulfide. The preparation method of Ni-Co-V complex was a combination of Ni-Co complex and the Ni-V complex. The amount of $\mathrm{Ni}\left(\mathrm{NO}_{3}\right)_{2} \cdot 6 \mathrm{H}_{2} \mathrm{O}$ and $\mathrm{Co}\left(\mathrm{NO}_{3}\right)_{2} \cdot 6 \mathrm{H}_{2} \mathrm{O}$ in this system were $218.107 \mathrm{mg}(0.75 \mathrm{mmol})$ and $10.91 \mathrm{mg}(0.0375 \mathrm{mmol})$, respectively. In order to explore the best ratio of $\mathrm{Ni}, \mathrm{Co}, \mathrm{V}$, different volumes of $\mathrm{VCl}_{3}$ concentrated solutions were added and the ratio of $\mathrm{Ni}, \mathrm{Co}$, and $\mathrm{V}$ were $20: 1: 1,20: 1: 1.5,20: 1: 2,20: 1: 2.5,20: 1: 3$. The subsequent operation was similar to the mention above. The Ni-Co-V complex was named NCV-BTC-1, NCV-BTC-2, NCV-BTC-3, NCV-BTC-4 and NCV-BTC-5. Ni-Co-V sulfide was prepared follow the above preparation method and they were named NCVS-1, NCVS-2, NCVS-3, NCVS-4, NCVS-5.

\subsection{Catalyst Characterization.}

The surface morphologies and compositions of the investigated materials were observed by field-emission scanning electron microscopy (FE-SEM) (Hitachi, SU8010). The transmission electron microscopy (TEM) characterization and electron diffraction 
analysis were prepared by JEM-JEOL2100F. The crystal structures of the samples were characterized using powder X-ray diffraction (XRD, Rigaku SmartLab (9 KW) diffractometer ( $\mathrm{Cu} \mathrm{Ka}$ radiation) at settings of $45 \mathrm{kV}$ and $200 \mathrm{~mA})$. Raman spectra were recorded on DXR2xi Raman imaging microscopy under an excitation of $532 \mathrm{~nm}$ laser light. The X-ray photoelectron spectroscopy (XPS) signals were obtained with a Thermo Escalab 250xi system with an Al Ka X-ray monochromator (1486.6 eV). The electrochemical test was carried out using Shanghai Chenhua CHI660E electrochemical workstation. Electrochemical impedance spectroscopy (EIS) analysis was performed on Autolab PGSTAT 302 (Metrohm, Switzerland).

\subsection{Preparation of working electrode}

In conventional electrochemical tests, carbon paper was used as working electrode. The carbon paper was first wash with a mixed solution of ethanol and acetone for $15 \mathrm{~min}$ in the ultrasound system, and then washed with ethanol and water two times. Finally, it was dry in oven. In the electrochemistry in-suit Raman test, in order to avoid background interference, copper foil was used as the working electrode. The specific method of pretreated copper foil was as follows. The cut copper foil was put into a tube furnace and annealed at $500{ }^{\circ} \mathrm{C}$ for $5 \mathrm{~h}$ in air. After natural cooling, the original orange-red copper foil surface turned dark gray and showed peeling phenomenon. After gently scraping off the peeled copper oxide on the surface with a blade, chronoamperometry electrochemical reduction method was used to obtain copper foil with rough surface.

The catalyst ink was prepared as follow, first, the grinded catalyst $(2 \mathrm{mg}$ ) was dispersed in $200 \mu \mathrm{L}$ of the mixed solution of water and isopropanol $\left(\mathrm{V}_{\text {water }}: \mathrm{V}_{\text {isopropanol }}=1: 3\right)$, 
then $20 \mu \mathrm{L}$ of Nafion solution $(0.5 \mathrm{wt} \%)$ was added. Ultrasound for $90 \mathrm{~min}$ to get evenly dispersed catalyst ink. Then, dropped $50 \mu \mathrm{L}$ catalyst ink on the carbon paper so that the catalyst loading was $0.5 \mathrm{mg} \mathrm{cm}{ }^{-2}$. The method of preparing the working electrode for in-situ Raman testing was similar to the above, except that carbon paper was replaced with copper foil.

\subsection{Electrochemical Measurement}

We carried out the electrochemical tests via a three-electrode configuration using Shanghai Chenhua CHI660E electrochemical workstation. Carbon paper loaded with catalyst was used as working electrode, $\mathrm{Hg} / \mathrm{HgO}$ electrode filled with $1 \mathrm{M} \mathrm{KOH}$ and a graphite rod electrode was used as reference electrode and counter electrode, respectively. The electrolyte was $1 \mathrm{M} \mathrm{KOH}$ and $0.33 \mathrm{M}$ urea. The measured potential was converted to RHE by the Nernst equation $\left(\mathrm{E}_{\mathrm{RHE}}=\mathrm{E}_{\mathrm{Hg} / \mathrm{HgO}}+0.059 * \mathrm{pH}+0.098\right)$ and the data were presented without iR correction unless otherwise specified because the solution resistance was very small $(\sim 1.3 \mathrm{ohm})$.

Before the catalytic test, the catalyst was activated through cyclic voltammetry $(\mathrm{CV})$ test in the potential range from $1.22 \mathrm{~V}$ to $1.82 \mathrm{~V}$ (vs. RHE) at the scan rate of $100 \mathrm{mV} \mathrm{s}^{-1}$ until the signal stabilizes. The evaluation of the electrocatalytic performance of materials was mainly carried out by linear sweep voltammetry method (LSV) at the scan rate of 5 $\mathrm{mV} \mathrm{s}^{-1}$.

The electrochemically active area (ECSA) of material was usually evaluated by its electric double layer capacitance $\left(\mathrm{C}_{\mathrm{dl}}\right)$. The specific method was as follows. The cyclic voltammetry $(\mathrm{CV})$ was performed in $1 \mathrm{M} \mathrm{KOH}$ at various scan rates of $20,40,60,80$, and 
$100 \mathrm{mV} \mathrm{s}^{-1}$ with the potential range of $1.0 \mathrm{~V} \sim 1.1 \mathrm{~V}$ (vs. RHE). A series of current density at $1.07 \mathrm{~V}$ (vs. RHE) depended on the scan rate were linear fitted by least square method, its slope value was the $\mathrm{C}_{\mathrm{d} \text { l }}$. Due to the uncertainty of the specific capacitance value $(\mathrm{Cs}), \mathrm{C}_{\mathrm{dl}}$ was used to measure the size of the ECSA according to the equation $1 .{ }^{1}$

$$
\mathrm{ECSA}=C_{d l} / C_{s}
$$

The electrochemical impedance spectroscopy (EIS) spectra were tested at $0.39 \mathrm{~V}$ (vs. RHE), with the frequency changing from $100 \mathrm{kHz}$ to $0.1 \mathrm{~Hz}$. The electrochemical stability of the materials was tested by two methods. The first one was chronoamperometry at the potential of $1.36 \mathrm{~V}$ (vs. RHE). The second one was the CV test for 2000 cycles at the scan rate of $100 \mathrm{mV} \mathrm{s}^{-1}$ in the electrolyte of $1 \mathrm{M} \mathrm{KOH}$ and $0.33 \mathrm{M}$ urea.

The electrochemical test at different temperatures was carried out by placing the electrolytic cell in a water bath with variable temperature. The LSV curves were test at different temperatures to obtain the relationship between current density and temperature, and the Arrhenius equation was used to calculate the apparent electrochemical activation energy of the material according to the following equation $2 .^{2}$

$$
\frac{-E_{a}}{2.3 R}=\left.\frac{\partial\left(\log i_{k}\right)}{\partial(1 / T)}\right|_{\eta}
$$

Where $E_{a}\left(\mathrm{~J} \mathrm{~mol}^{-1}\right)$ is the apparent electrochemical activation energy. $k$ is the reaction rate constant at the temperature of $T . T(\mathrm{~K})$ is the temperature of electrolyte. $i_{k}$ $(\mathrm{mA})$ is the kinetic current at a potential of $1.5 \mathrm{~V}(\mathrm{vs} . \mathrm{RHE}), R\left(\mathrm{~J} \mathrm{~mol}^{-1} \mathrm{~K}^{-1}\right)$ is the universal gas constant.

In-situ electrochemistry Raman spectra were recorded with DXR2xi Raman system and the wavelength of excitation laser was $532 \mathrm{~nm}$. The test was carried out in a 
custom-made electrolytic cell with the processed copper foil as the working electrode, $\mathrm{Ag} / \mathrm{AgCl}$ electrode and platinum wire as the reference electrode and the counter electrode, respectively. $1 \mathrm{M} \mathrm{KOH}$ and $0.33 \mathrm{M}$ urea was used as electrolyte. Raman spectra were recorded under chronoamperometry.

\subsection{Measurement of hydrogen production}

Gas chromatography was used to detect the hydrogen concentration, and the hydrogen generation rate was calculated according to equation 3 .

$$
C_{H_{2}}=\frac{V_{A r} \times x}{1000 \times m_{c}}
$$

Where $C_{H_{2}}$ is the concentration of $\mathrm{H}_{2}\left(\mathrm{~L} \mathrm{~min}^{-1} \mathrm{~g}^{-1}\right.$ cat $) . V_{A r}$ is the flow rate of Argon (sccm). $x$ is the volume fraction of hydrogen, it can be obtained by using the ratio of the hydrogen peak area of the actual sample and standard gas. $m_{c}$ is the loading amount of catalyst (g). In this experiment, the flow rate of argon gas was $20 \mathrm{sccm}$, the hydrogen content in the standard gas was $0.2 \%$, and the catalyst loading on carbon paper was $0.5 \mathrm{mg}$.

\subsection{Calculation of TOF values for materials}

For convenience, we considered all metal sites for the calculation of turnover frequencies (TOF). On the working electrode, the mass $(m)$ of the material was $0.5 \mathrm{mg}$. According to the actual ratio of metal elements in the material measured by ICP-AES, the chemical formulas of NS, NCS-6, NVS-1 and NCVS-3 can be written as $\mathrm{NiS}_{2}$ $\mathrm{Ni}_{0.952} \mathrm{Co}_{0.048} \mathrm{~S}_{2}, \mathrm{Ni}_{0.991} \mathrm{~V}_{0.009} \mathrm{~S}_{2}$ and $\mathrm{Ni}_{0.926} \mathrm{Co}_{0.058} \mathrm{~V}_{0.017} \mathrm{~S}_{2}$, corresponding Molar mass (M) were 122.83 (NS), 122.84 (NCS-6), 122.76 (NVS-1) and $122.77 \mathrm{~g} \mathrm{~mol}^{-1}$ (NCVS-3), respectively. The molar of metal $(n)$ was calculated according to $\mathrm{n}=\mathrm{m} / \mathrm{M}$. The current density $(j)$ at $1.5 \mathrm{~V}$ (vs. RHE) was used to calculate the amount of electricity that each 
metal site can provide, and the electrode surface area (A) was around $1 \mathrm{~cm}^{-2}$. The electricity required to convert one molecule of urea was $6 \mathrm{e}$. TOF values were calculated using the following equation 4 :

$$
\mathrm{TOF}=\frac{j A}{6 n N_{A} e}=\frac{j A}{6 n F}
$$

\subsection{DFT calculation}

When carried out DFT calculation, gradient approximation (GGA) method with Perdew-Burke-Ernzerhof (PBE) functional were employed. ${ }^{3}$ The van der Waals interactions were estimated by using DFT-D3 method with. ${ }^{4}$ Energy cut-off was set to 400 $\mathrm{eV}$. The $\mathrm{NiS}_{2}(001)$ surfaces with $(2 \times 2 \times 2)$ cell were modeled, and Gamma k-point was adopted. A vacuum space of $10 \AA$ in the z-direction was set to minimize interactions among neighboring substrate images. The atoms of top layer were fully relaxed to optimize the thermodynamic stable structure. The free energy of the intermediate species were evaluated using the computational hydrogen electrode method reported by Norskov et al. ${ }^{5}$ In this method, the free energy of $\mathrm{H}^{+}(\mathrm{aq})+\mathrm{e}^{-}$at the standard state was calculated with the free energy of $1 / 2 \mathrm{H}_{2}(\mathrm{~g})$ according to the definition of reversible hydrogen electrode. The free energy $\mathrm{OH}^{-}(\mathrm{aq})$ was obtained from the reaction $\mathrm{H}_{2} \mathrm{O}(\mathrm{l})=\mathrm{H}^{+}(\mathrm{aq})+\mathrm{OH}^{-}(\mathrm{aq})$. The $\Delta \mathrm{G}$ value can be determined as follows: $\Delta \mathrm{G}=\Delta \mathrm{E}+\Delta \mathrm{ZPE}-\mathrm{T} \Delta \mathrm{S}+\Delta \mathrm{G}_{\mathrm{pH}}+e U$, where $\Delta \mathrm{E}$ is the electronic energy difference directly obtained from DFT calculations, $\triangle \mathrm{ZPE}$ is the change in zero-point energies, $\mathrm{T}$ is the temperature $(\mathrm{T}=298.15 \mathrm{~K})$, and $\Delta \mathrm{S}$ is the entropy change. $\Delta \mathrm{G}_{\mathrm{pH}}$ is the correction of the $\mathrm{OH}^{-}$free energy by the concentration, which can be determined as $\Delta \mathrm{G}_{\mathrm{pH}}=2.303 \times k_{\mathrm{B}} \mathrm{T} \times \mathrm{pH}($ or $0.059 \times \mathrm{pH})$, where $k_{\mathrm{B}}$ is the Boltzmann constant and the value of $\mathrm{pH}$ was assumed to be 13, the terms $e$ and $U$ are the number of 
electrons transferred and the applied electrode potential, respectively. The Gibbs free energy in Figure 5c for each reaction step was calculated at the standard conditions $(U=0$ V).

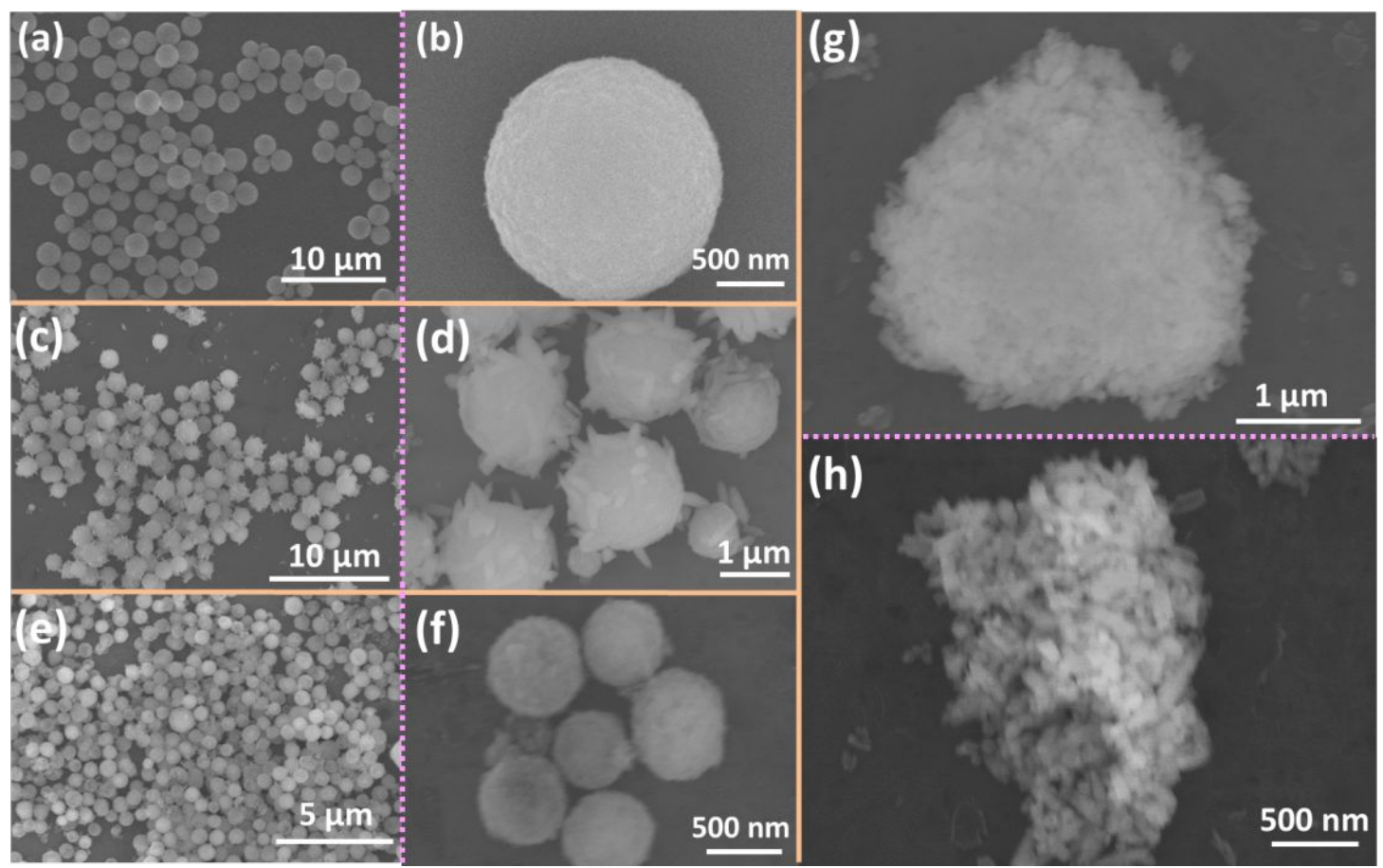

Figure S1. SEM images of $(a, b)$ N-BTC; $(c, d)$ NC-BTC-6; (e,f) NV-BTC-1 and $(g, h)$ NCV-BTC-3.

N-BTC was sphere with rough surface and the uniform size was $2 \mu \mathrm{m}$. However, many spines appeared on the surface of the sphere after introducing Co element (NC-BTC). The morphology of NV-BTC was smaller ball with size around $1 \mu \mathrm{m}$. The morphology of NCV-BTC turned into irregular short stick. 
(a)

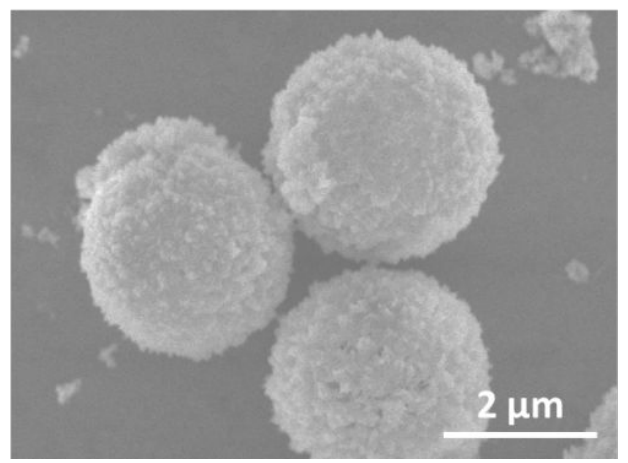

Figure S2. $(a, b)$ SEM images of NC-BTC-1. (b)

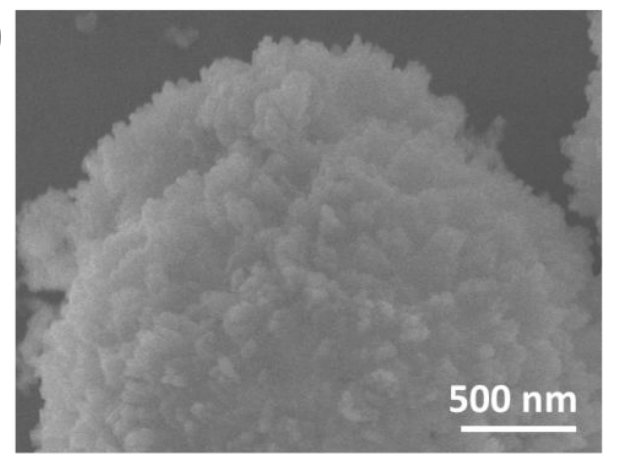

With the amount of Co increased, the

surface of NC-BTC became rougher.

(a)

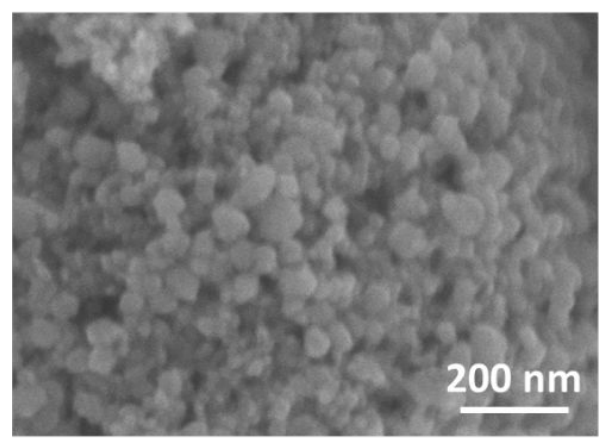

(c)

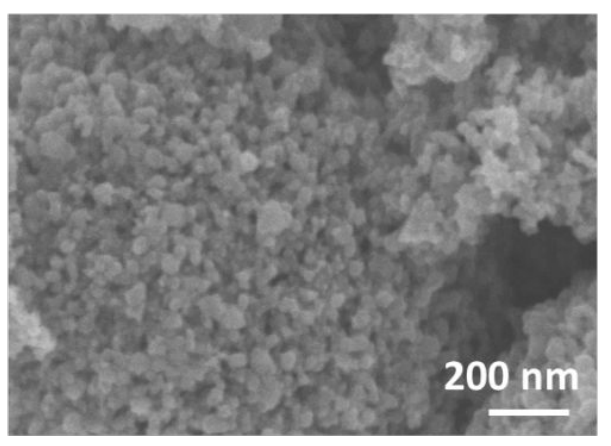

(b)

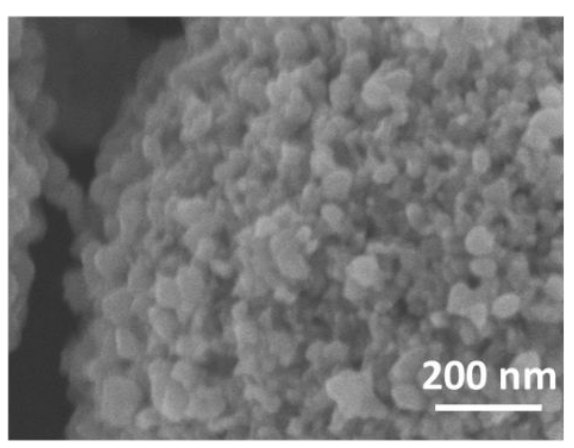

(d)

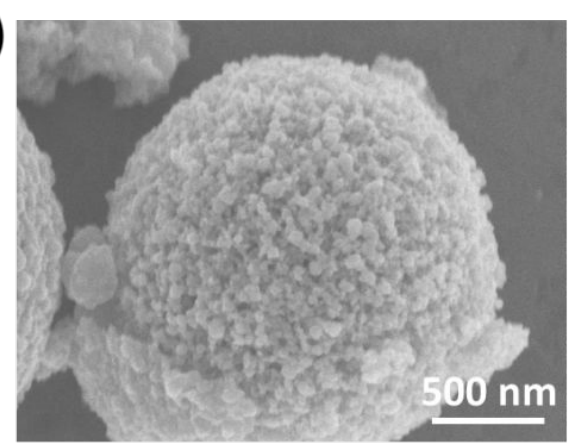

Figure S3. SEM images of $\mathrm{NiS}_{2}$ obtained from N-BTC precursor with hydrothermal reaction for (a) $12 \mathrm{~h}$; (b) $24 \mathrm{~h}$; (c) $36 \mathrm{~h}$; (d) $48 \mathrm{~h}$. 


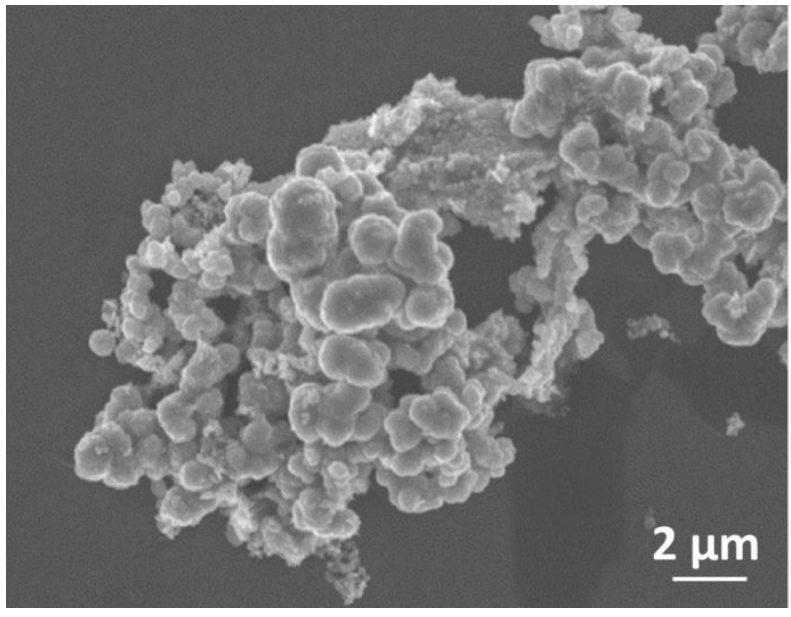

Figure S4. (a) SEM image of $\mathrm{NiS}_{2}$ obtained from the direct reaction of $\mathrm{Ni}\left(\mathrm{NO}_{3}\right)_{2} \cdot 6 \mathrm{H}_{2} \mathrm{O}$ and thioacetamide.

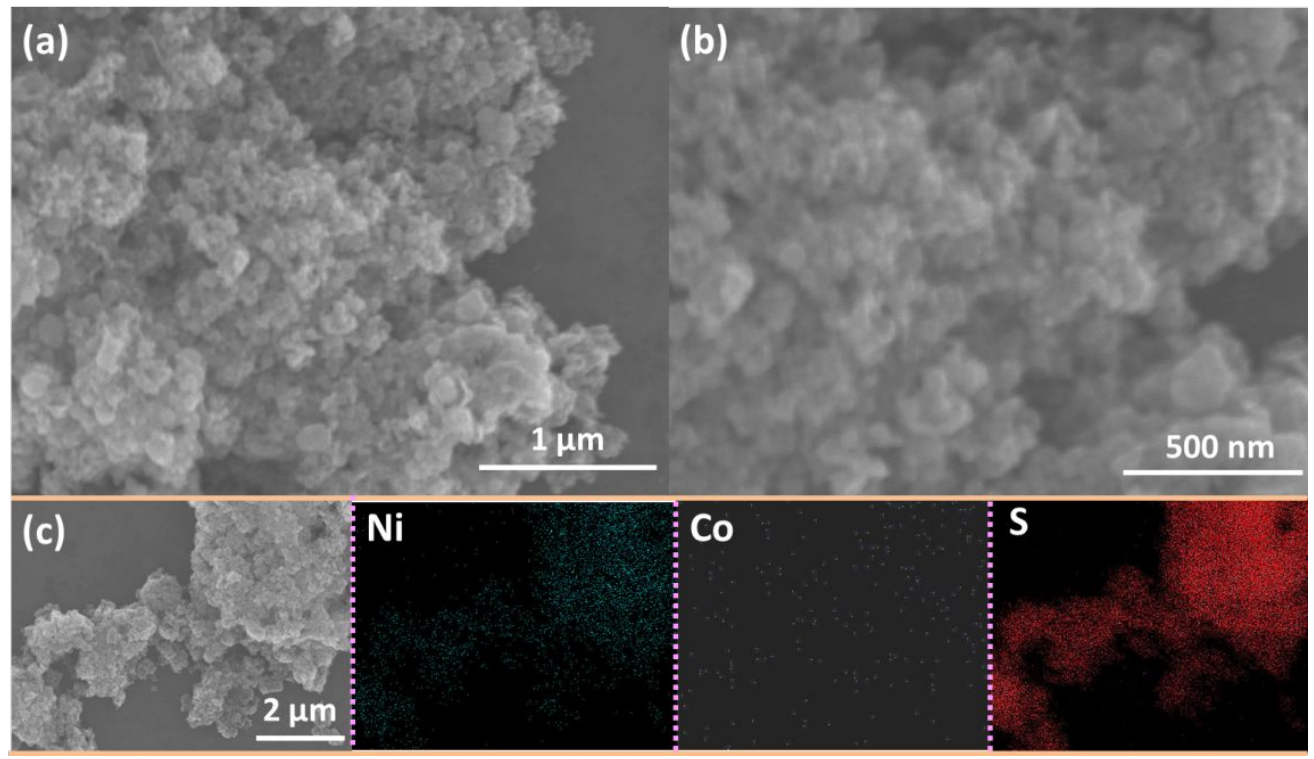

Figure S5. (a, b) SEM images of NCS-6; (c) SEM image and corresponding elemental mappings of NCS-6. 


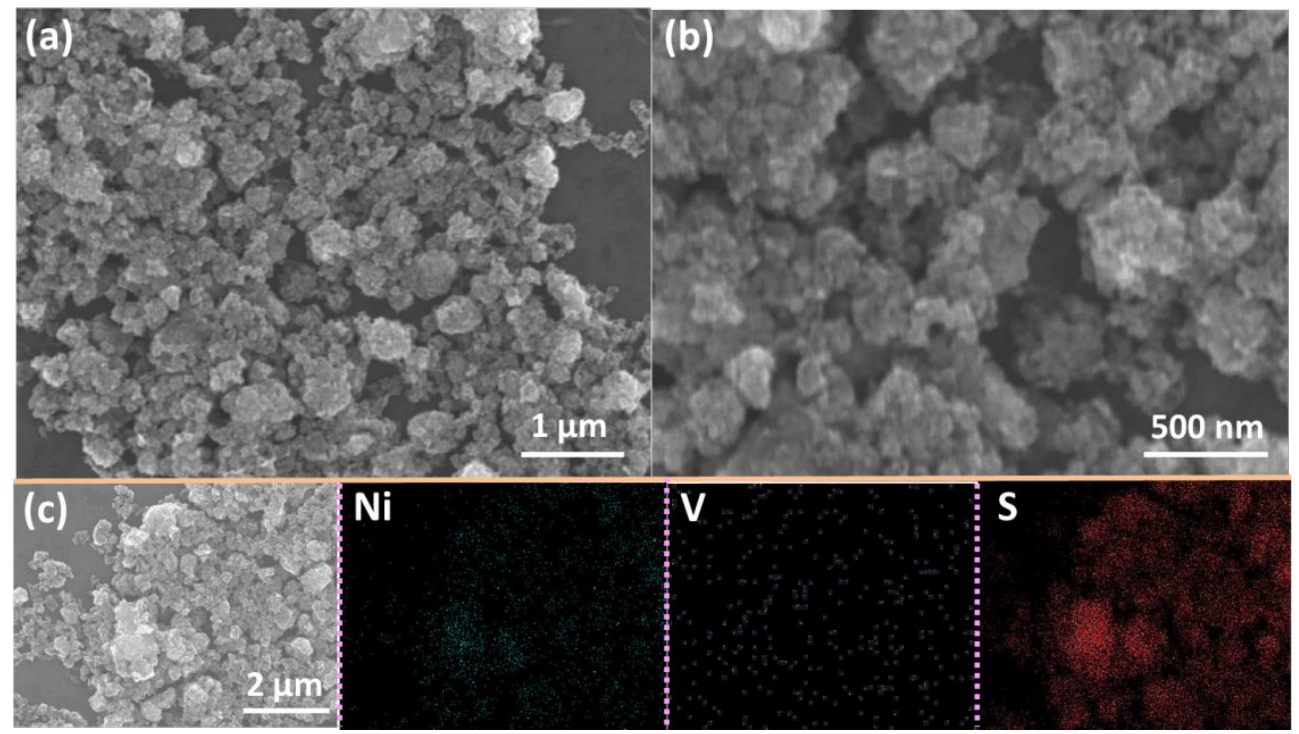

Figure S6. (a, b) SEM images of NVS-1; (c) SEM image and corresponding elemental mappings of NVS-1. 


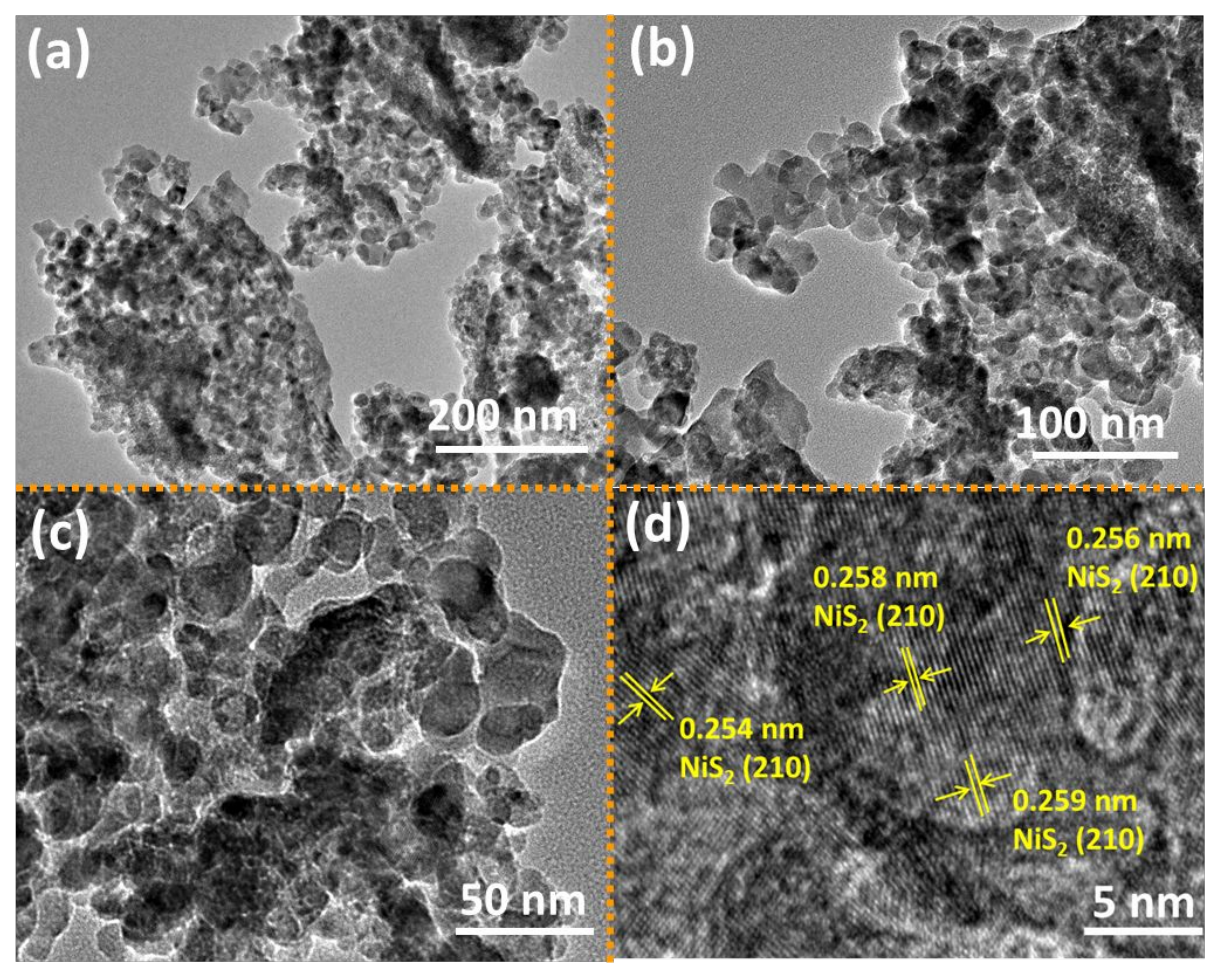

Figure S7. (a-c) TEM images of NS; (d) HRTEM image of NS. The lattice fringe space of $\sim 2.54 \AA$ assigned to the $\mathrm{NiS}_{2}$ (210) plane. In the absence of heteroatoms, (210) was the mainly exposed crystal plane. 


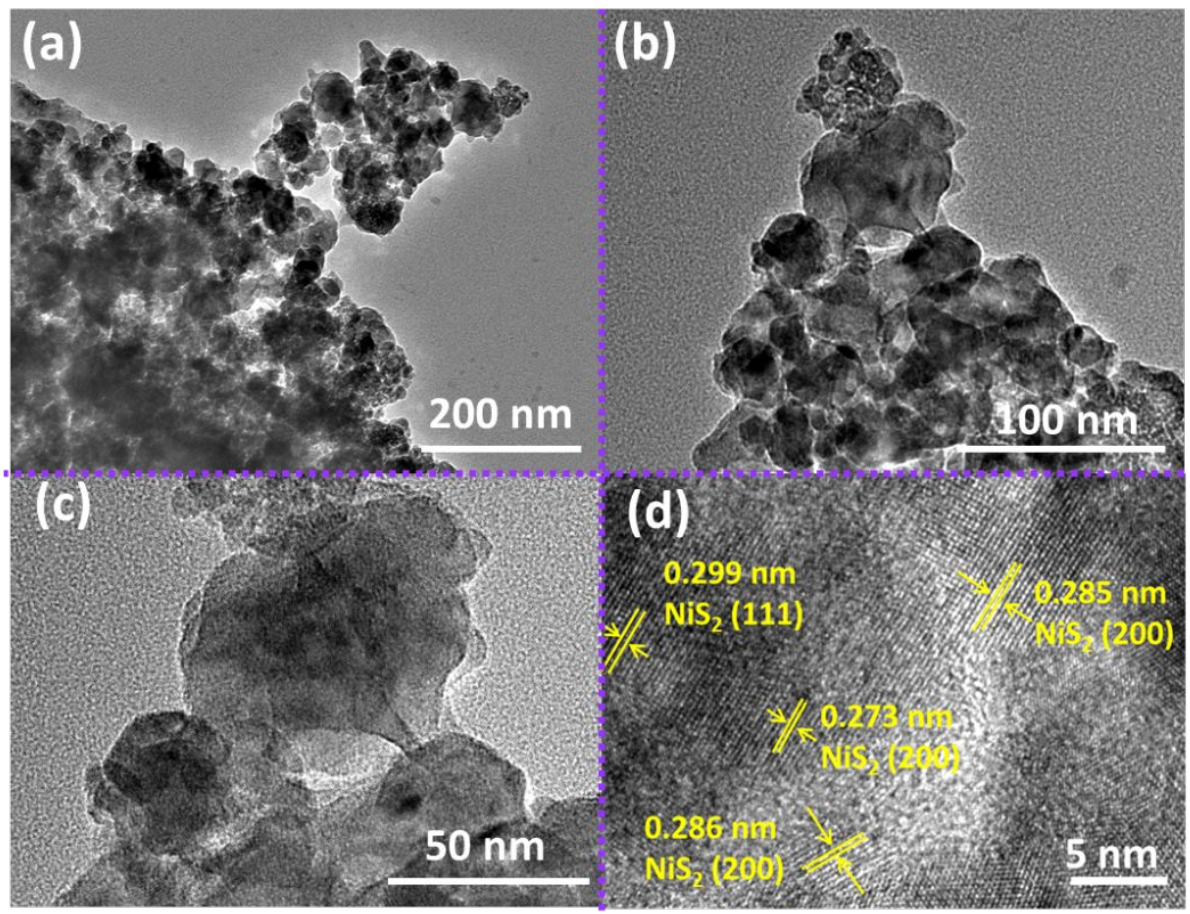

Figure S8. (a-c) TEM images of NCS-6; (d) HRTEM image of NCS-6. The lattice fringe space of $\sim 2.86 \AA$ and $\sim 2.73 \AA$ assigned to the $\mathrm{NiS}_{2}$ (200) plane. After introduced Co element, the main exposed crystal plane of $\mathrm{NiS}_{2}$ changed from (210) to (200) and $\mathrm{Co}$ element caused a certain degree of lattice shrinkage. 


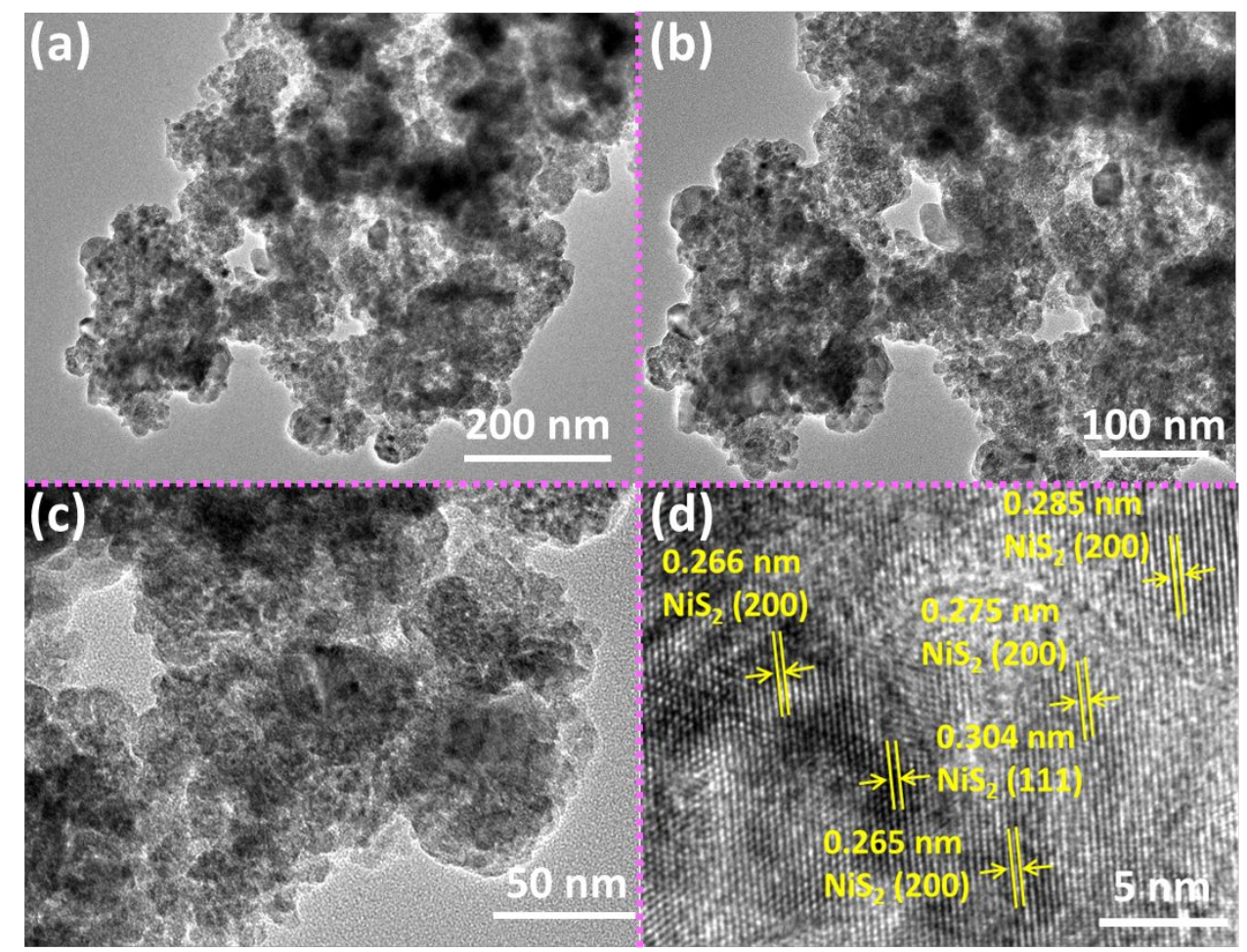

Figure S9. (a-c) TEM images of NVS-1; (d) HRTEM image of NVS-1. The lattice fringe space of $\sim 2.85 \AA$ and $\sim 2.65 \AA$ assigned to the $\mathrm{NiS}_{2}$ (200) plane. After introduced V element, the main exposed crystal plane of $\mathrm{NiS}_{2}$ changed from (210) to (200) and $\mathrm{V}$ element caused a greater degree of lattice shrinkage. 

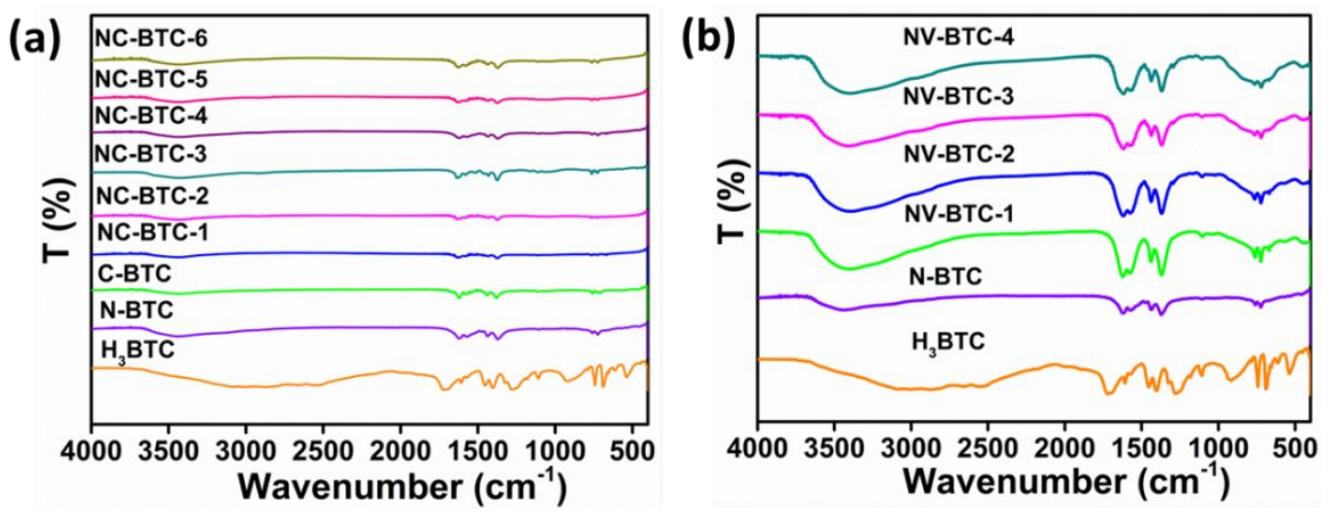

Figure S10. Infrared spectroscopy of (a) $\mathrm{H}_{3}$ BTC, N-BTC, C-BTC and a series of NC-BTC;

(b) $\mathrm{H}_{3} \mathrm{BTC}$, N-BTC and a series of NV-BTC.

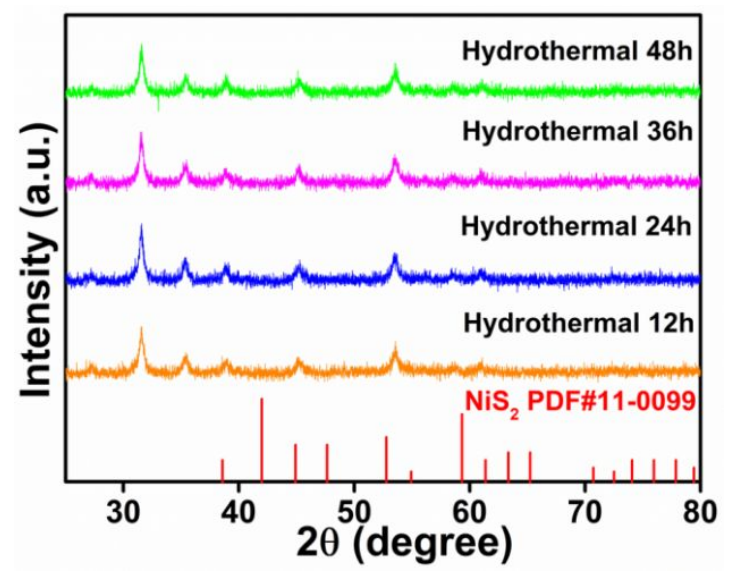

Figure S11. XRD pattern of $\mathrm{NiS}_{2}$ obtained from N-BTC precursor with hydrothermal reaction for $12 \mathrm{~h}, 24 \mathrm{~h}, 36 \mathrm{~h}, 48 \mathrm{~h}$. 

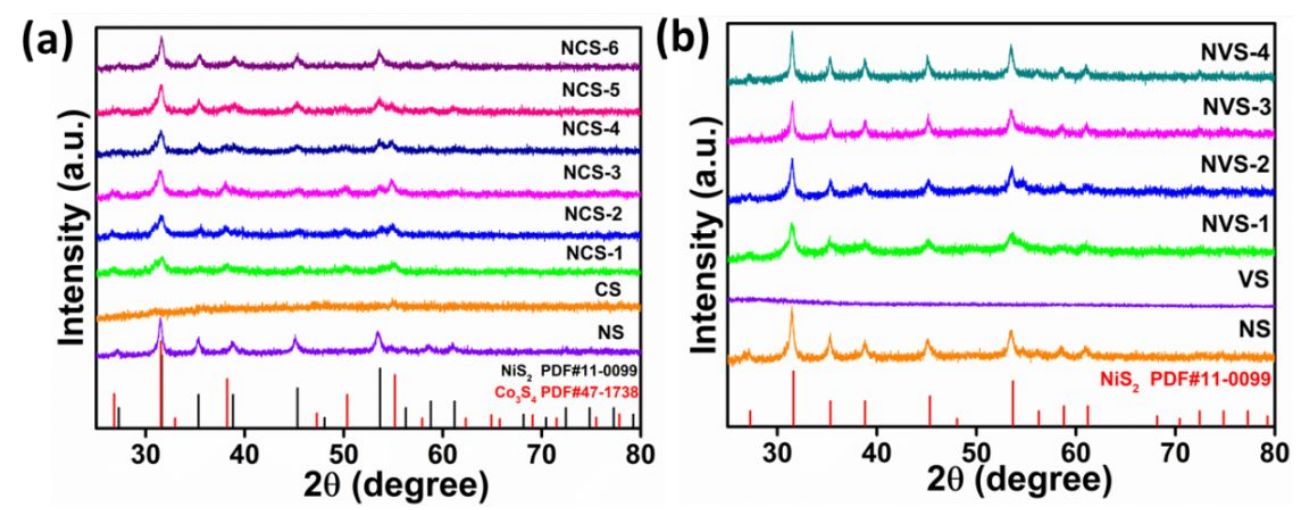

Figure S12. XRD patterns of (a) NS, CS and a series of NCS; (b) NS, VS and a series of NVS.
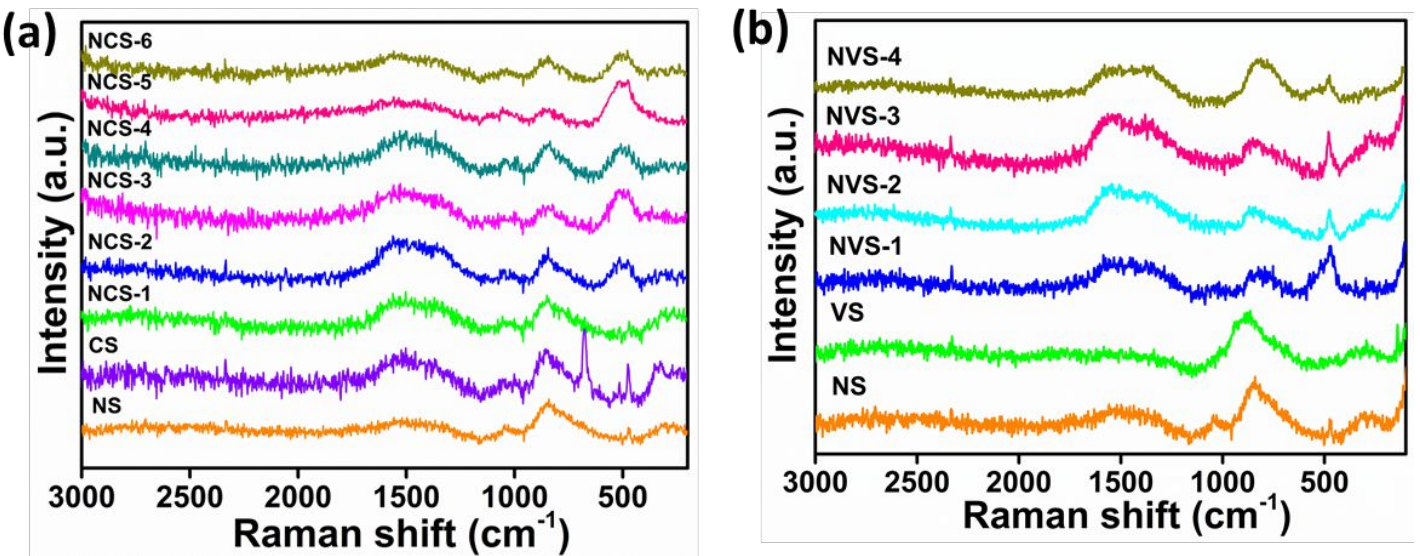

Figure S13. Raman spectra of (a) NS, CS and a series of NCS; (b) NS, VS and a series of NVS. 

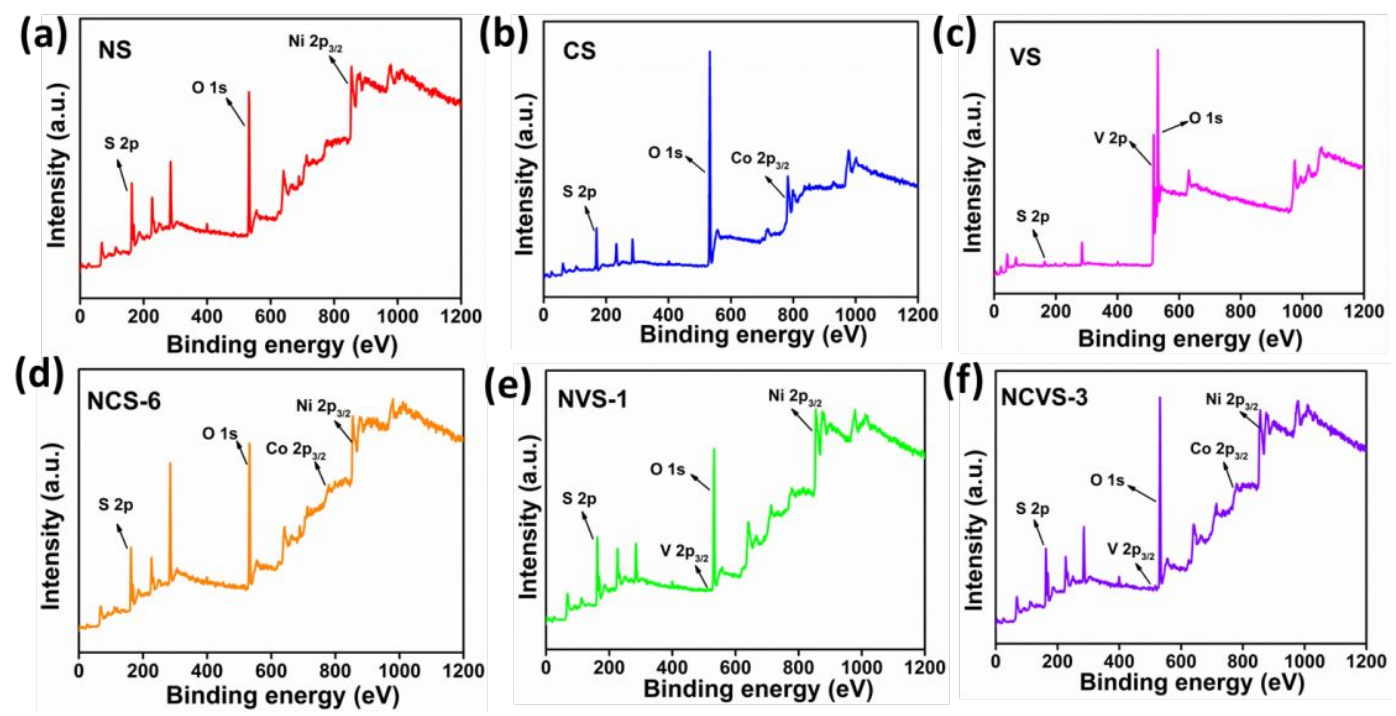

Figure S14. The XPS survey spectra of (a) NS; (b) CS; (c) VS; (d) NCS-6; (e) NVS-1 and (f) NCVS-3.
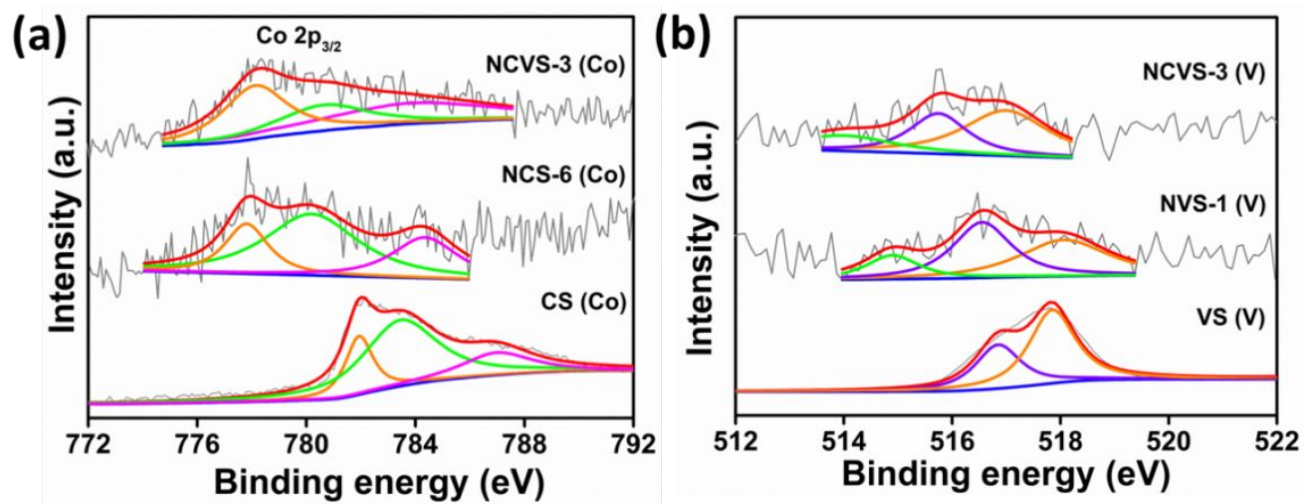

Figure S15. Co $2 p_{3 / 2}$ XPS spectra of CS, NCS-6 and NCVS-3; (b) V 2 $p_{3 / 2}$ XPS spectra of VS, NVS-1 and NCVS-3. 

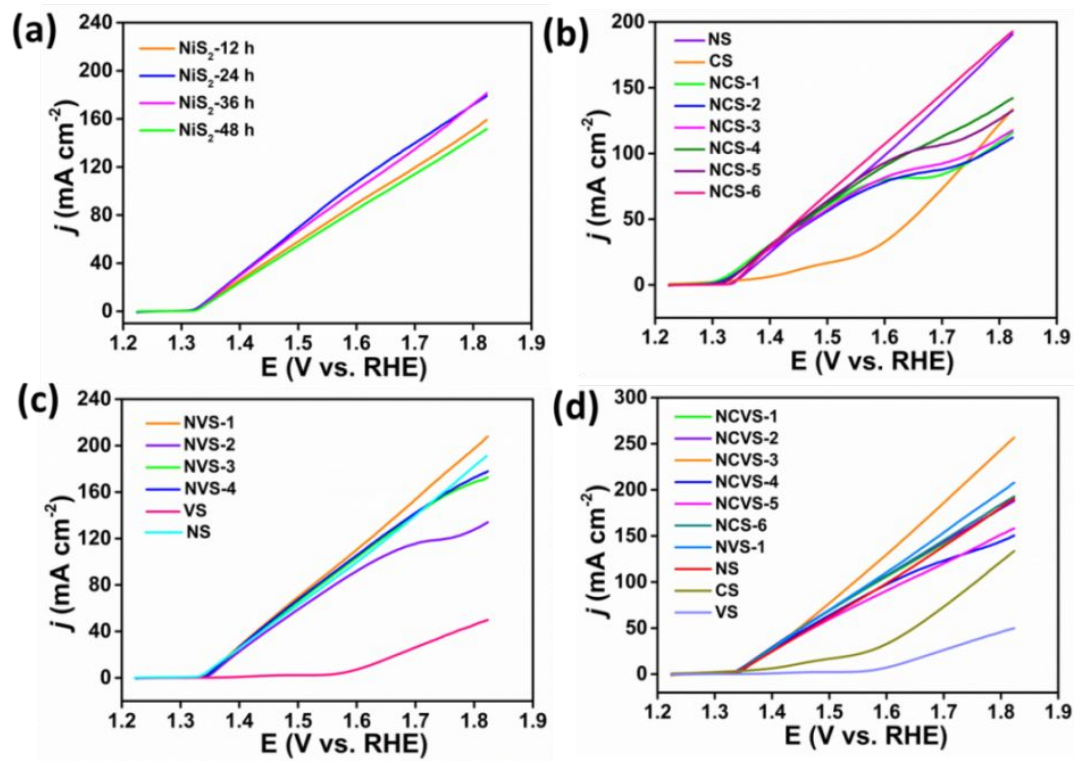

Figure S16. (a) LSV curves of $\mathrm{NiS}_{2}$ obtained by hydrothermal reaction for $12 \mathrm{~h}, 24 \mathrm{~h}, 36 \mathrm{~h}$, $48 \mathrm{~h}$ with N-BTC as the precursor in $1 \mathrm{M} \mathrm{KOH}$ and $0.33 \mathrm{M}$ urea. LSV curves of (b) NS, CS and a series of NCS; (c) NS, VS and a series of NVS; (d) NS, CS, VS, NCS-6, NVS-1 and a series of NCVS. 

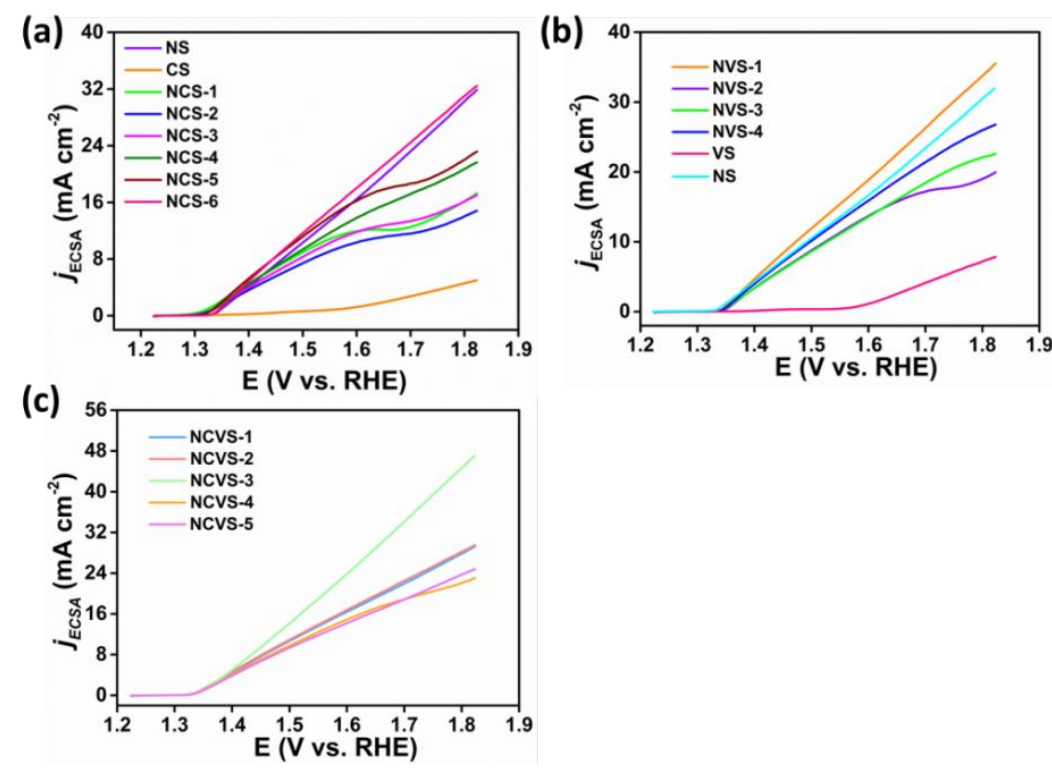

Figure S17. ECSA normalized current density of (a) NS, CS and a series of NCS; (b) NS, VS and a series of NVS; (c) a series of NCVS.

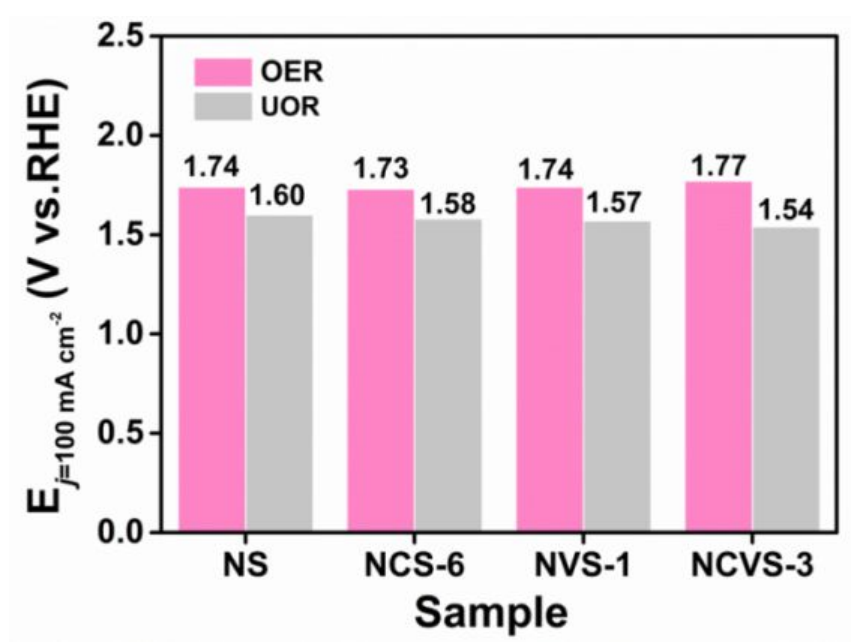

Figure S18. The comparison of potential when the current density of OER or UOR reached $100 \mathrm{~mA} \mathrm{~cm}{ }^{-2}$ catalyzed by NS, NCS-6, NVS-1 and NCVS-3 

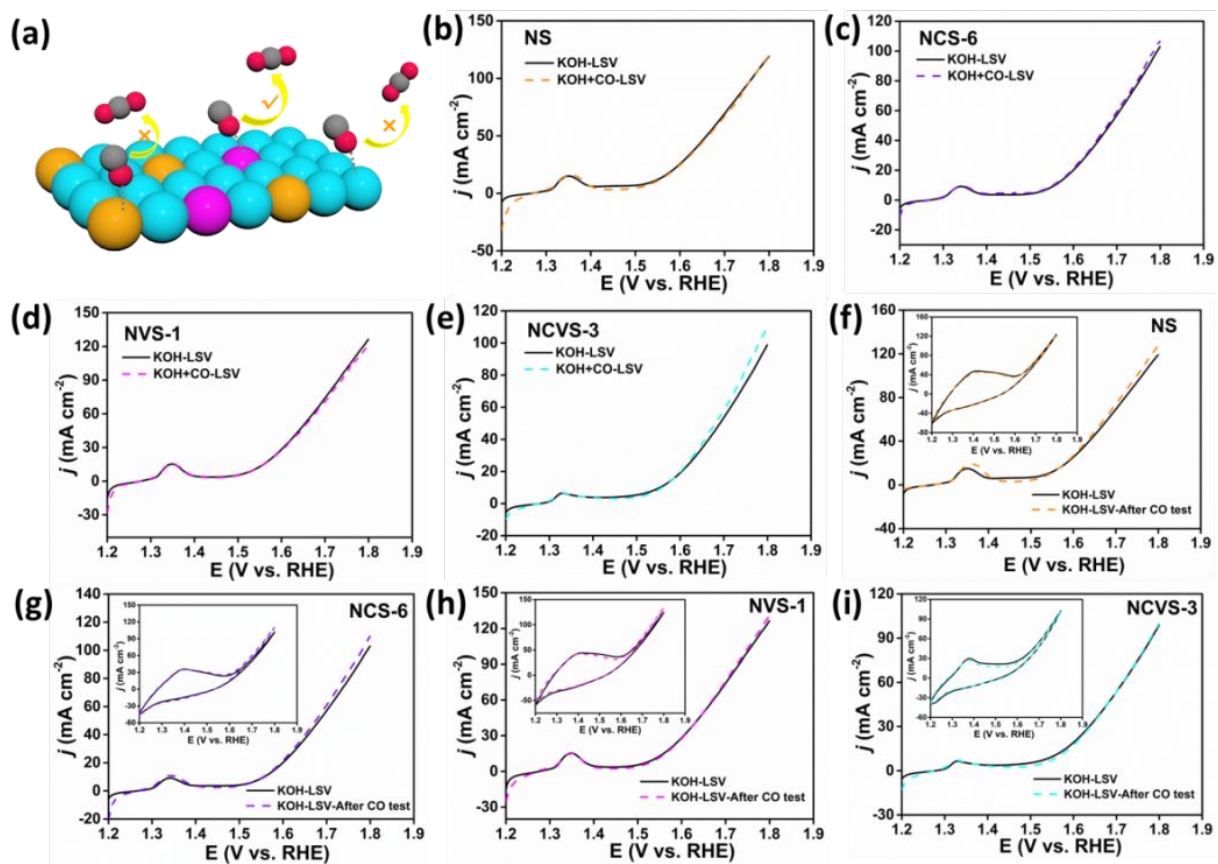

Figure S19. (a) Schematic diagram of the oxidation of carbon monoxide-like intermediate generated during the oxidation of urea on $\mathrm{Ni}, \mathrm{Co}, \mathrm{V}$ atoms (blue: $\mathrm{Ni}$, pink: Co, yellow: V); LSV curves of (b) NS; (c) NCS-6; (d) NVS-1; (e) NCVS-3 in the electrolyte of $1 \mathrm{M} \mathrm{KOH}$ with (dotted line) and without (solid line) $\mathrm{CO}$ bubbling at the scan rate of $5 \mathrm{mV} \mathrm{s}^{-1}$; LSV curves and CV curves (inset) of (f) NS; (g) NCS-6; (h) NVS-1; (i) NCVS-3 before (solid line) and after (dotted line) CO electro-oxidation test. 


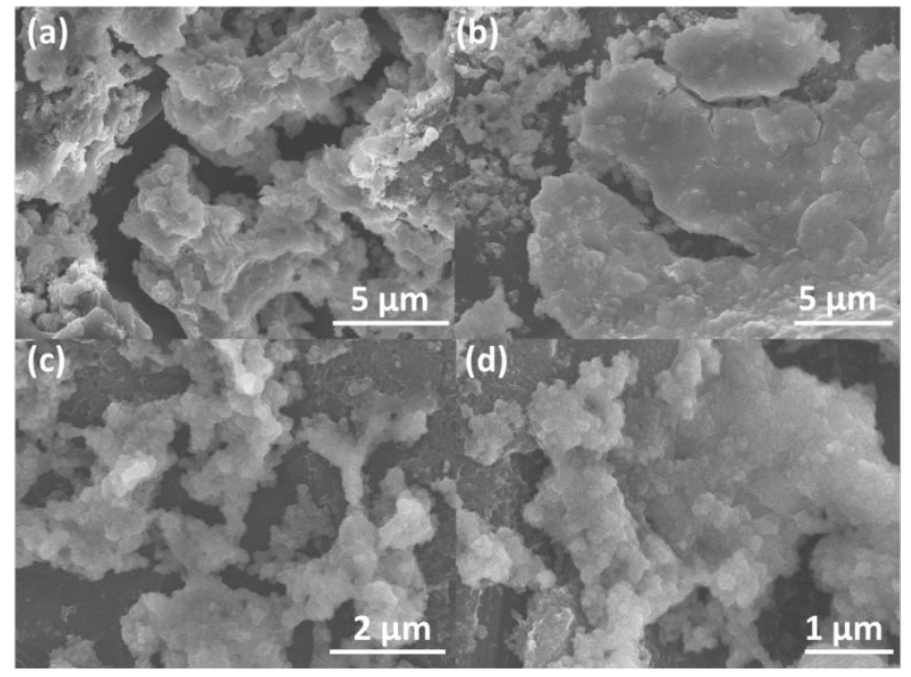

Figure S20. SEM images of (a,b) NVS-1 and (c,d) NCVS-3 after electrolysis for $10 \mathrm{~h}$.
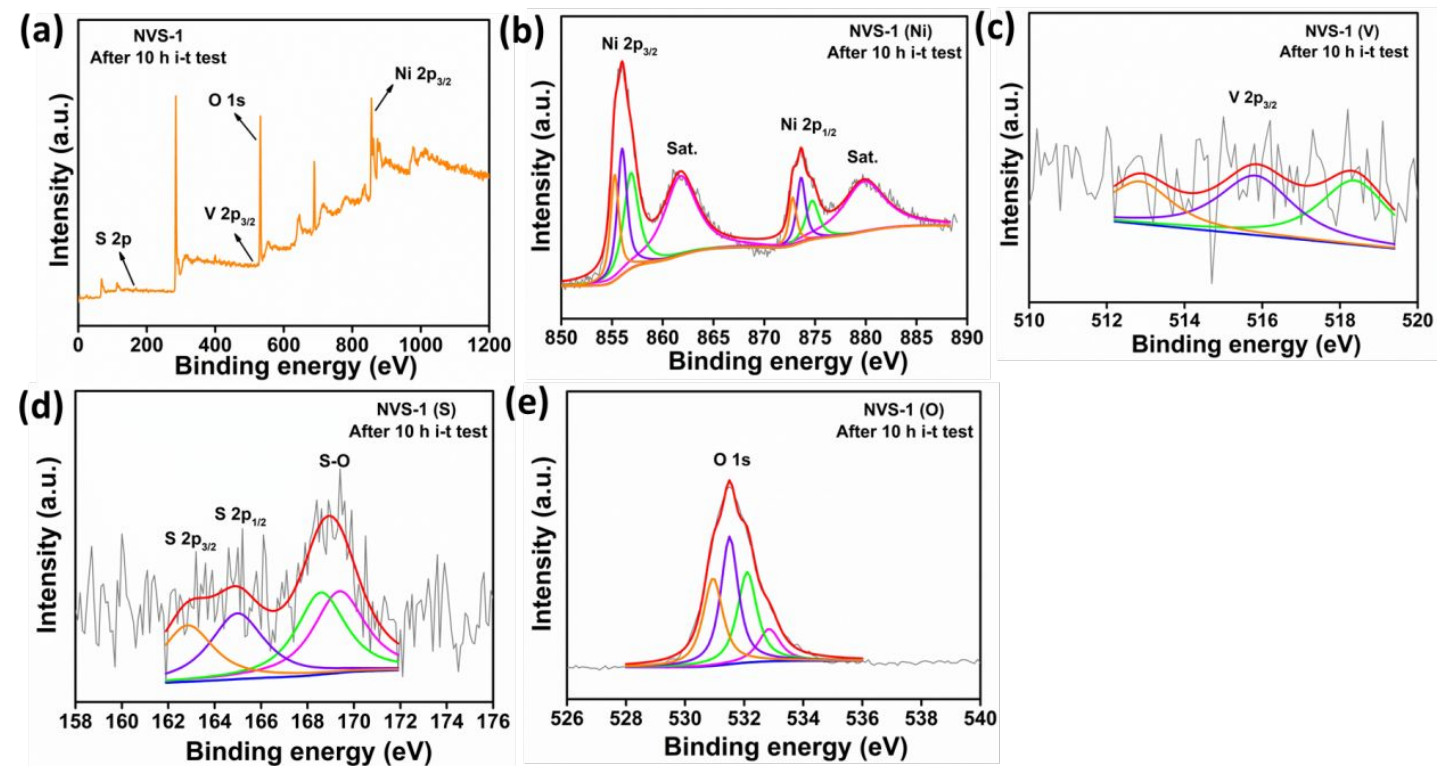

Figure S21. (a) The XPS survey spectrum of NVS-1 after electrolysis for $10 \mathrm{~h}$ and the corresponding high resolution spectra of (b) Ni 2p; (c) V 2p $3 / 2$; (d) S 2p; (e) O 1s. 

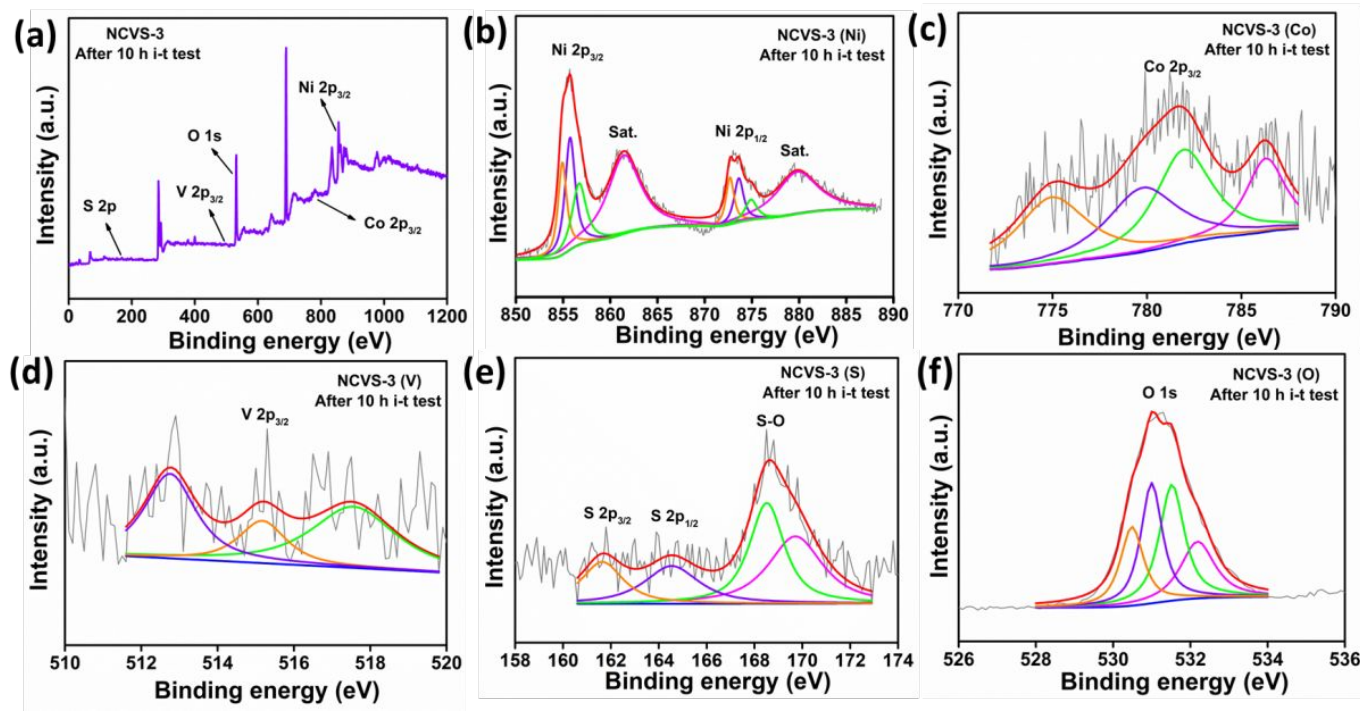

Figure S22. (a) The XPS survey spectrum of NCVS-3 after electrolysis for $10 \mathrm{~h}$ and the corresponding high resolution spectra of (b) Ni 2p; (c) Co 2p $\mathrm{p}_{3 / 2}$; (d) V 2 $\mathrm{p}_{3 / 2}$; (e) $\mathrm{S} 2 \mathrm{p}$; (f) $\mathrm{O}$ $1 \mathrm{s.}$

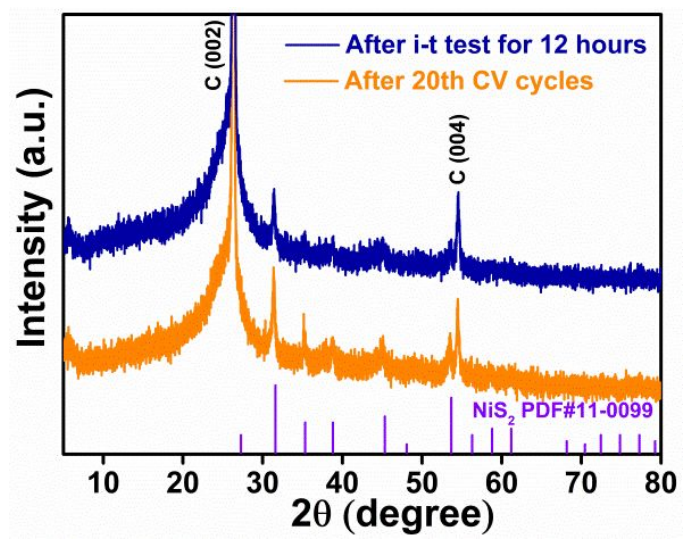

Figure S23. XRD patterns of NCVS-3 after $20 \mathrm{CV}$ cycles and 12-hour i-t test in $1 \mathrm{M} \mathrm{KOH}$ and $0.33 \mathrm{M}$ urea. 

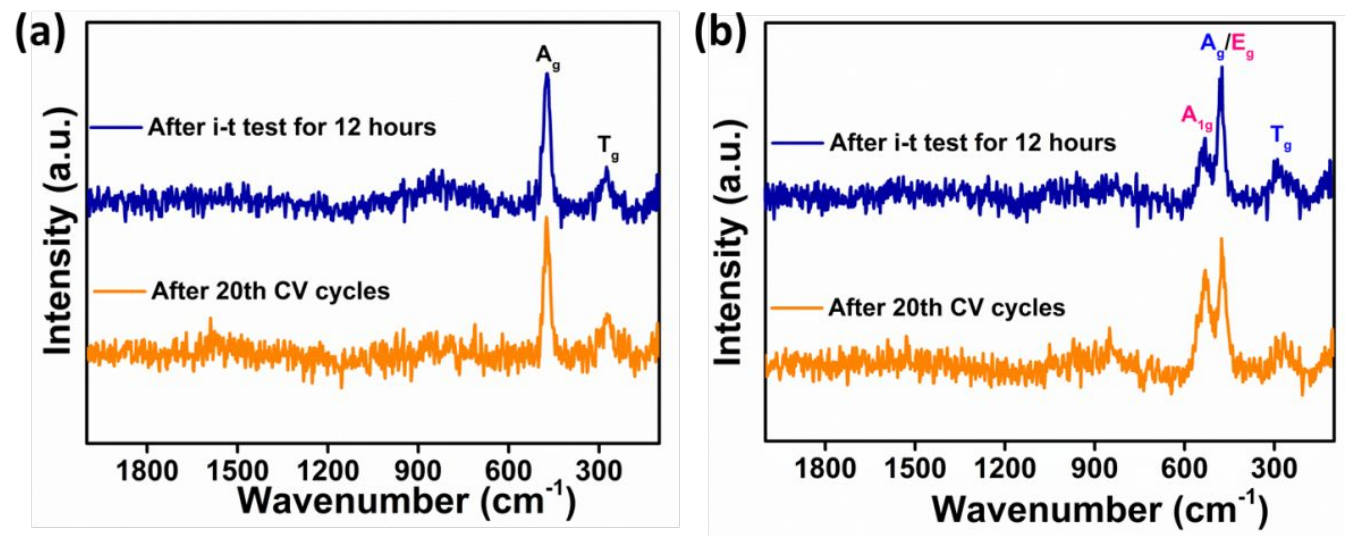

Figure S24. Raman spectra of NCVS-3 after $20 \mathrm{CV}$ cycles and 12-hour i-t test in $1 \mathrm{M} \mathrm{KOH}$ and $0.33 \mathrm{M}$ urea at different positions.

(a)

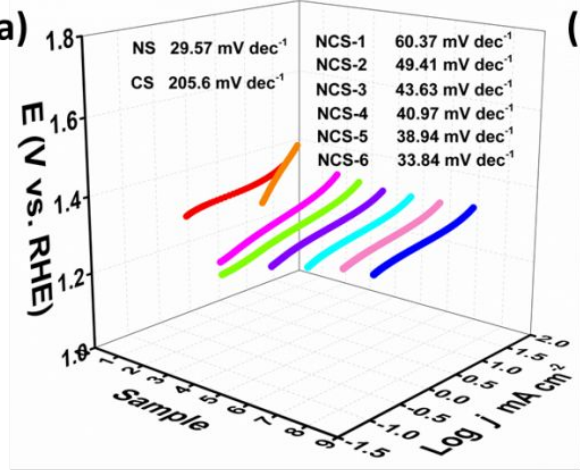

(b)

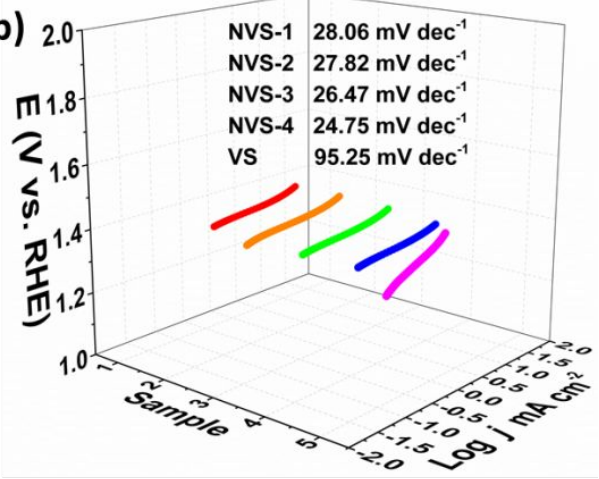

(c)

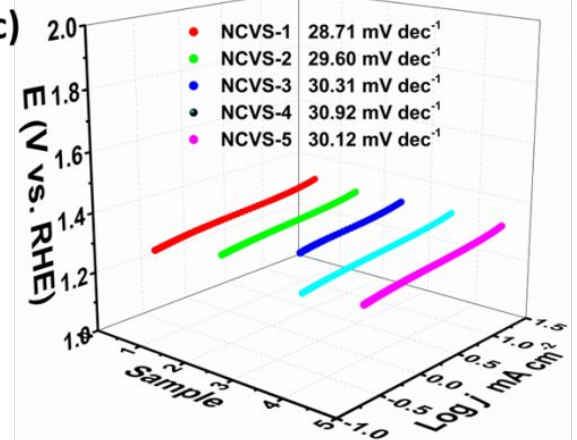

Figure S25. Tafel plots of (a) NS, CS and a series of NCS; (b) VS and a series of NVS; (c) a series of NCVS derived from the LSV curves. 

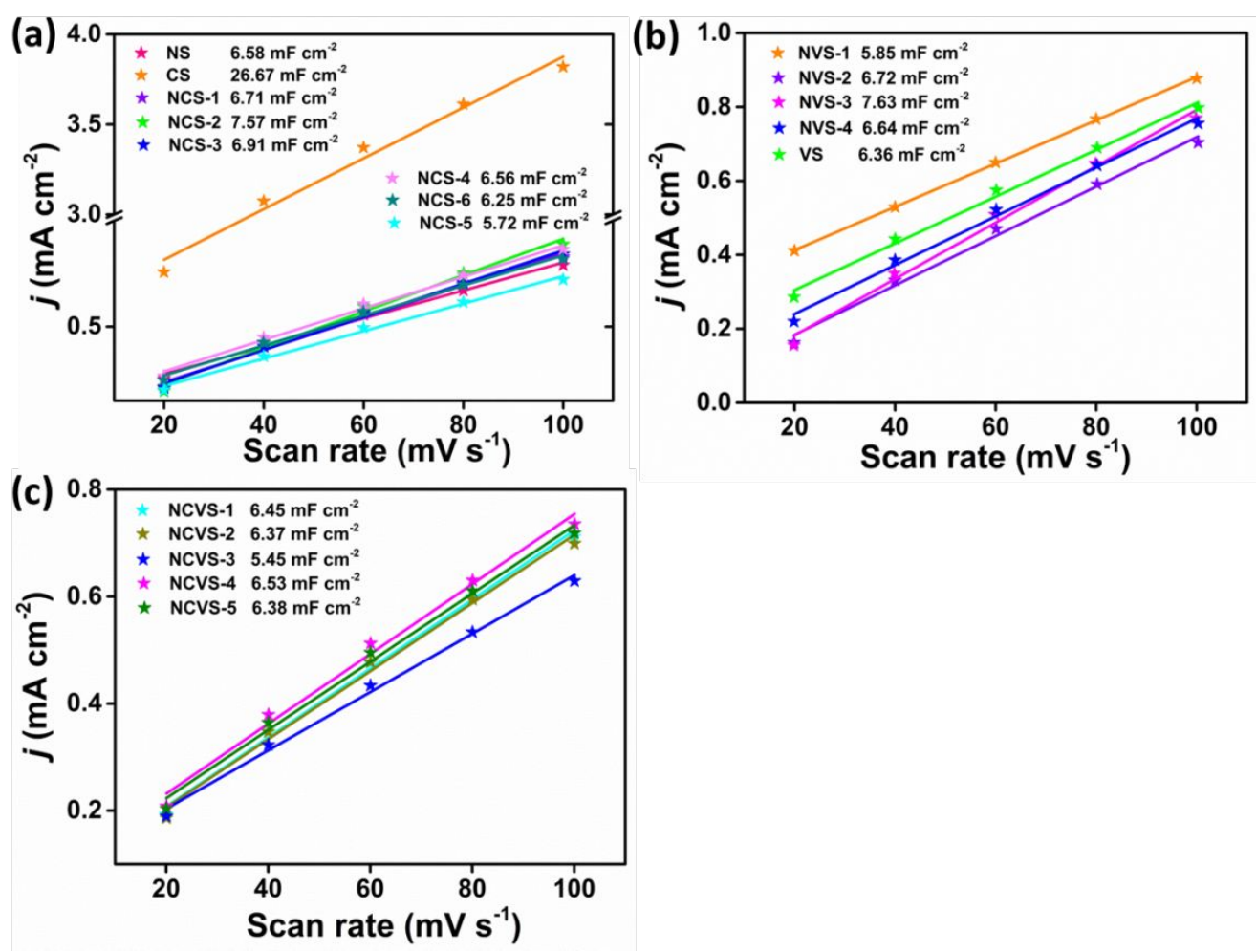

Figure S26. Double-layer capacitance $\left(C_{d l}\right)$ of (a) NS, CS and a series of NCS; (b) VS and a series of NVS; (c) a series of NCVS estimated by the scan rate-dependent current densities 

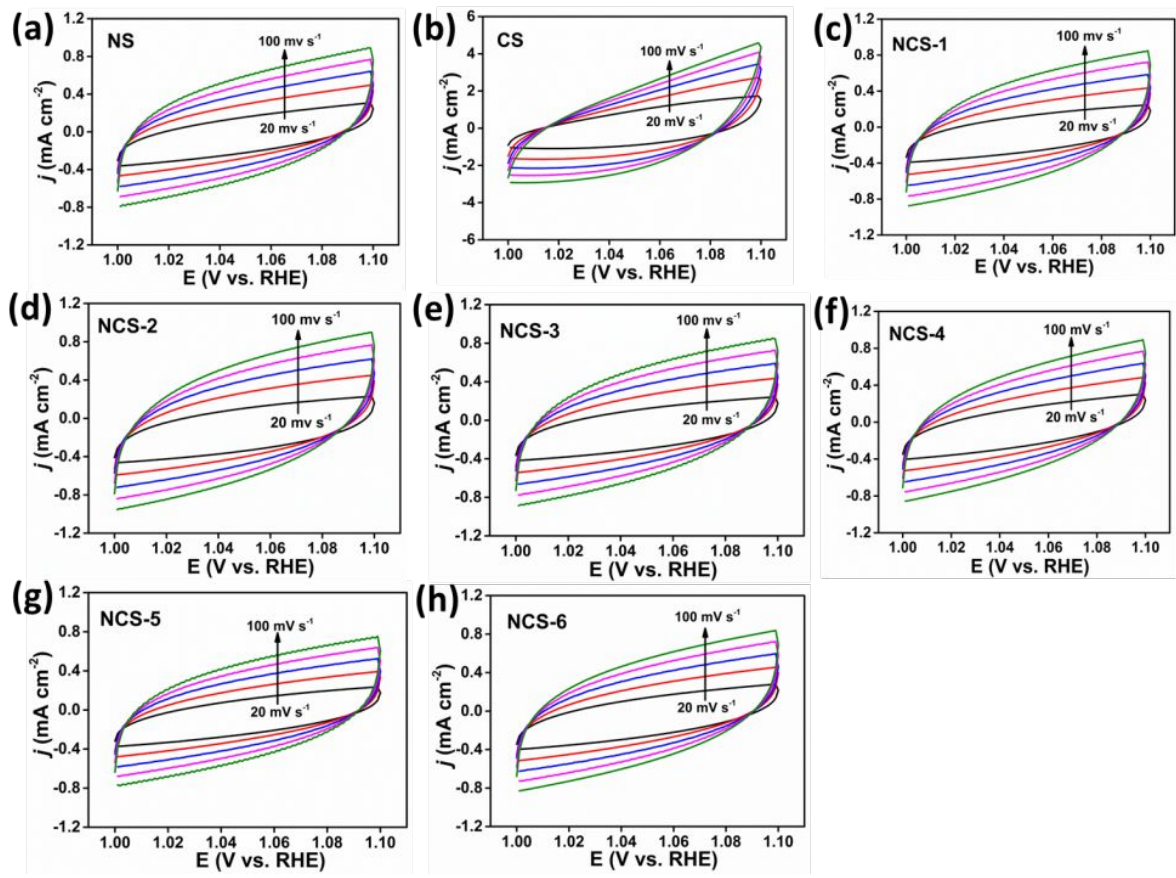

Figure S27. The CV cycles of NS, CS and a series of NCS measured at the scan rates of 20, $40,60,80$ and $100 \mathrm{mV} \mathrm{s}^{-1}$ in the potential region of 1.0 1.1 V (vs. RHE), respectively. 

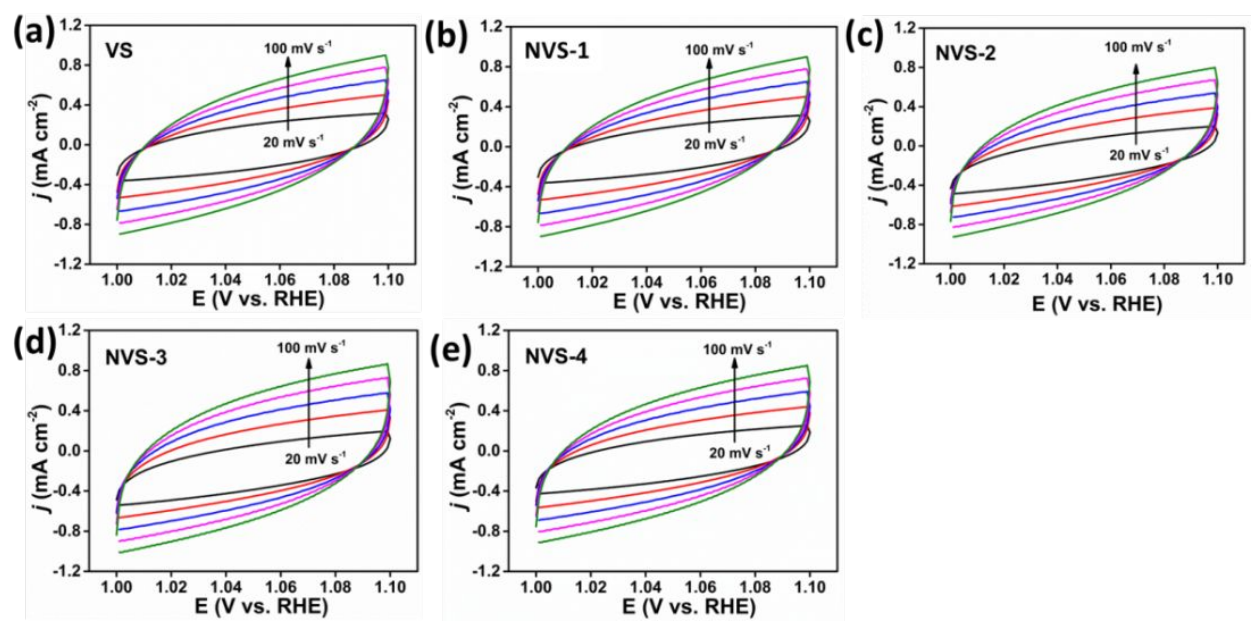

Figure S28. The CV cycles of VS and a series of NVS measured at the scan rates of 20, 40,

60,80 , and $100 \mathrm{mV} \mathrm{s}^{-1}$ in the potential region of 1.0 1.1 V (vs. RHE), respectively.
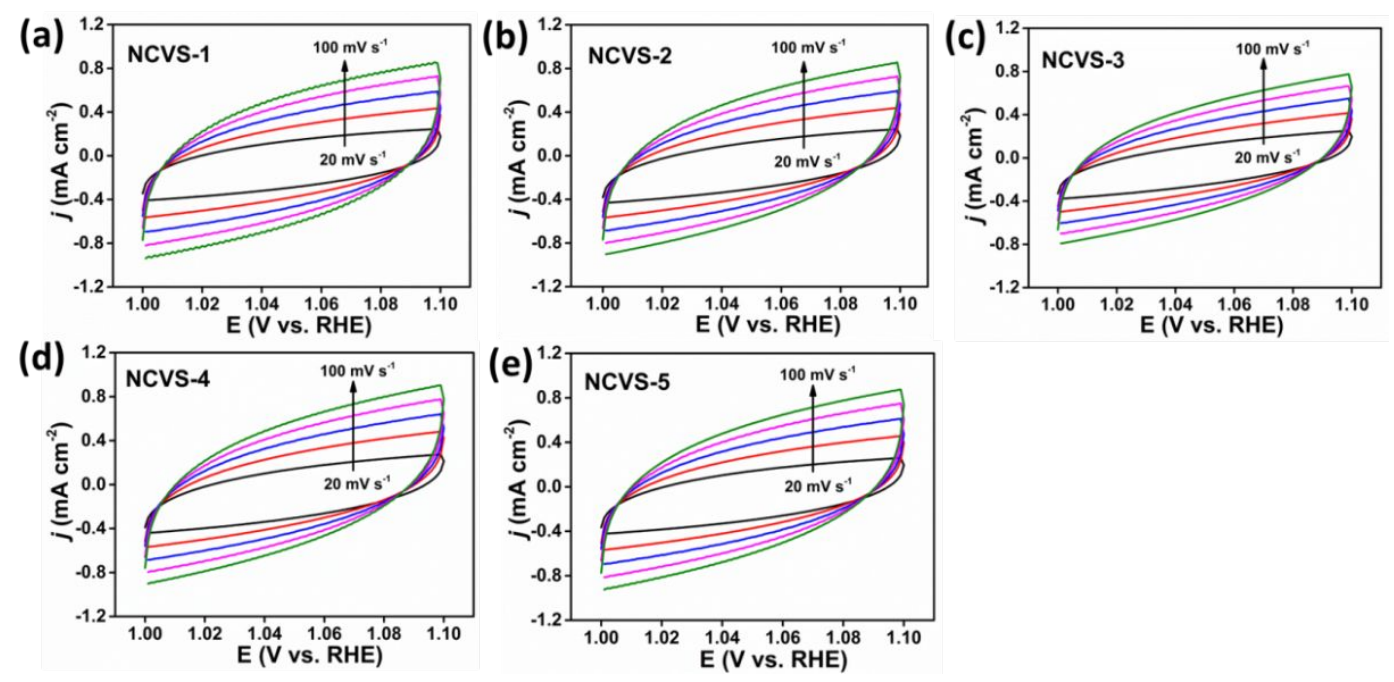

Figure S29. The CV cycles of a series of NCVS measured at the scan rates of 20, 40, 60, 80 , and $100 \mathrm{mV} \mathrm{s}^{-1}$ in the potential region of 1.0 1.1 V (vs. RHE), respectively. 


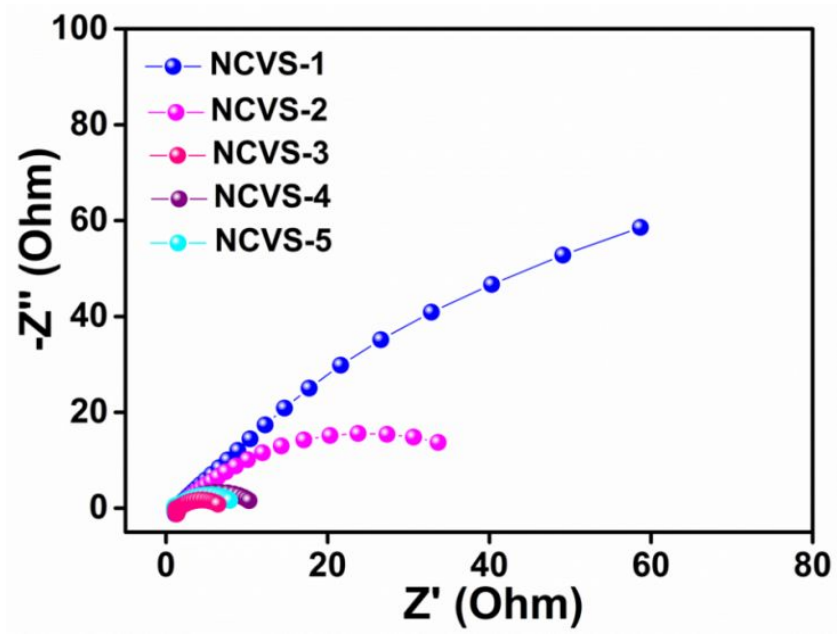

Figure S30. Nyquist plots of a series of NCVS.
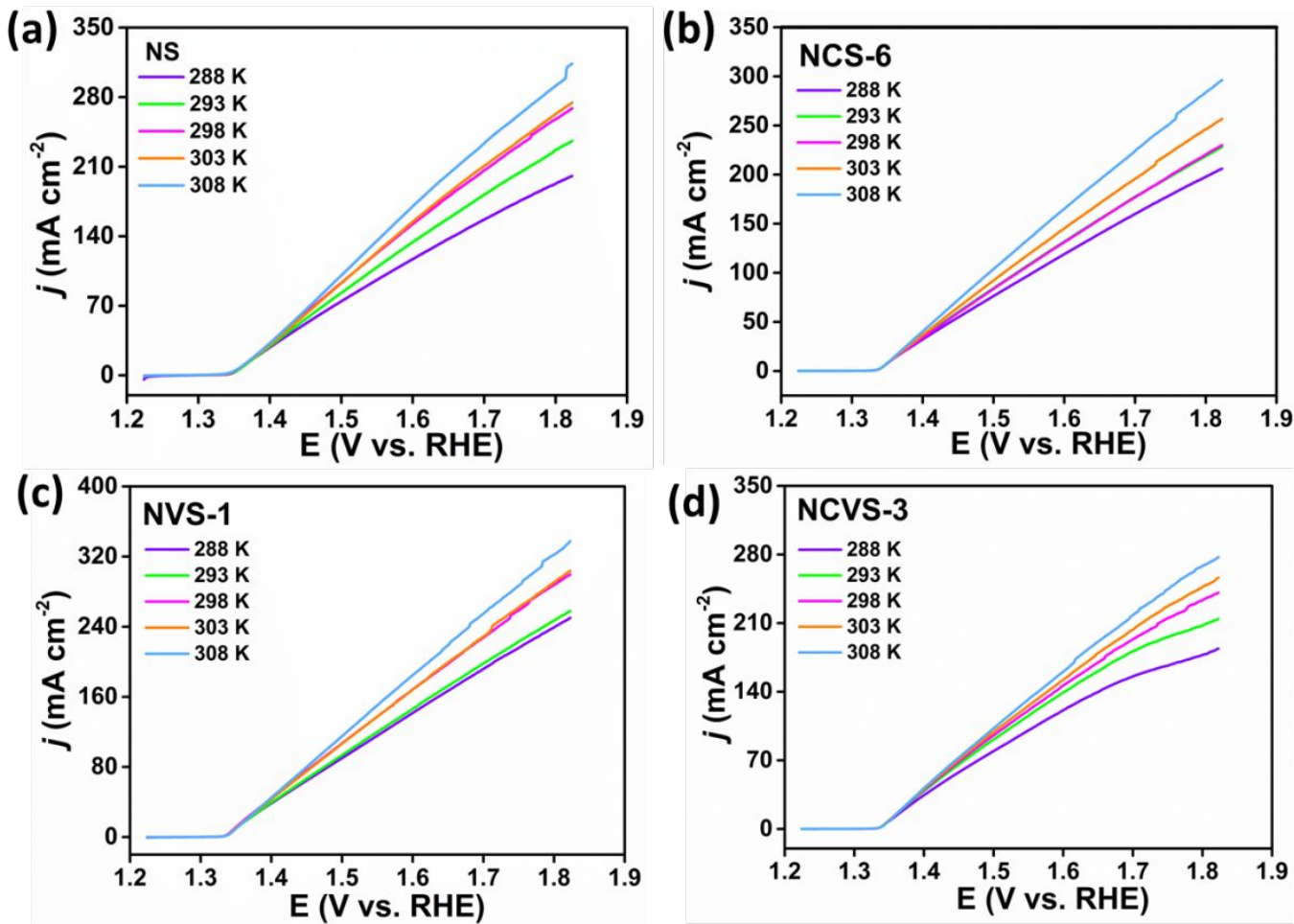

Figure S31. LSV curves of (a) NS; (b) NCS-6; (c) NVS-1 and (d) NCVS-3 in the electrolyte of $1 \mathrm{M} \mathrm{KOH}$ and $0.33 \mathrm{M}$ urea at the temperature of $288 \mathrm{~K}, 293 \mathrm{~K}, 298 \mathrm{~K}, 303 \mathrm{~K}$, $308 \mathrm{~K}$ and $313 \mathrm{~K}$, respectively. 

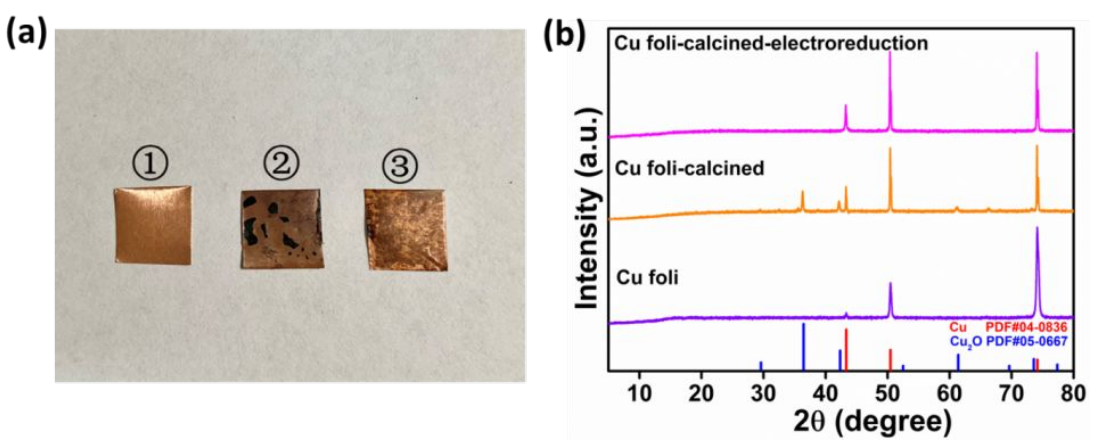

Figure S32. (a) Optical photo of $\mathrm{Cu}$ foil. (1) fresh $\mathrm{Cu}$ foil, (2) $\mathrm{Cu}$ foil after calcined at 500 ${ }^{\circ} \mathrm{C}$ for $5 \mathrm{~h}$ in air (3) calcined $\mathrm{Cu}$ foil after electroreduction; (b) XRD patterns of corresponding $\mathrm{Cu}$ foil.

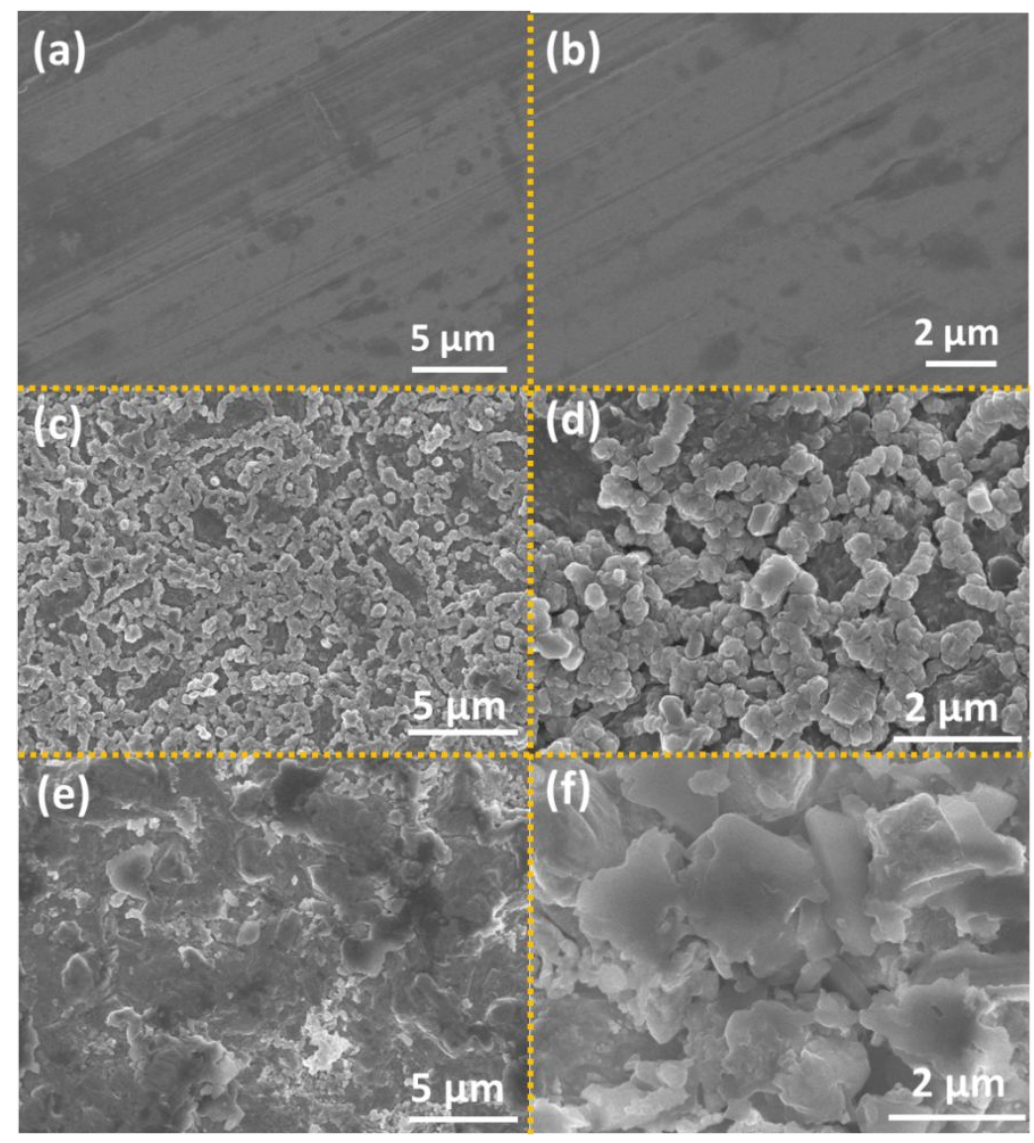

Figure S33. SEM images of (a,b) fresh $\mathrm{Cu}$ foil; $(\mathrm{c}, \mathrm{d}) \mathrm{Cu}$ foil after calcined at $500{ }^{\circ} \mathrm{C}$ for $5 \mathrm{~h}$ in air; $(\mathrm{e}, \mathrm{f})$ calcined $\mathrm{Cu}$ foil after electroreduction. 


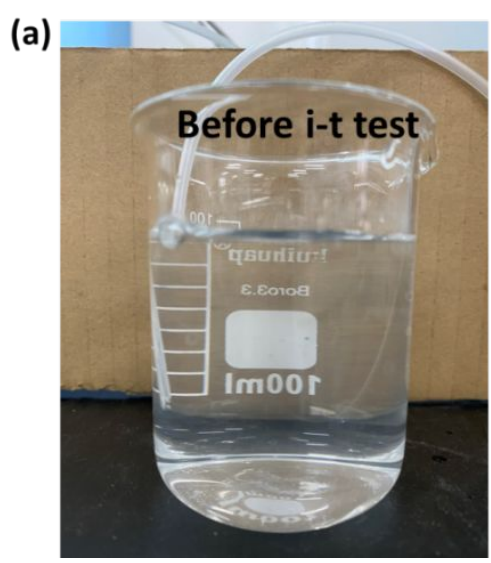

(b)

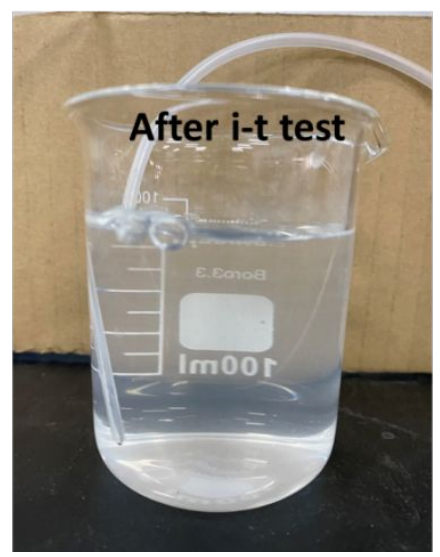

Figure S34. (a) Clarified saturated $\mathrm{Ca}(\mathrm{OH})_{2}$ solution; (b) After chronoamperometry (i-t) test of UOR for $2 \mathrm{~h}$, the saturated $\mathrm{Ca}(\mathrm{OH})_{2}$ solution became turbid indicating that the gas product contained $\mathrm{CO}_{2}$.

(a)

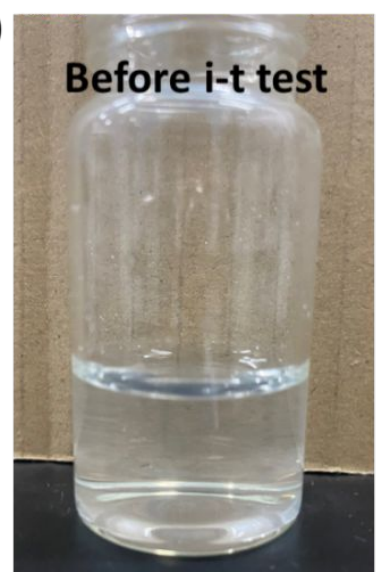

(b)

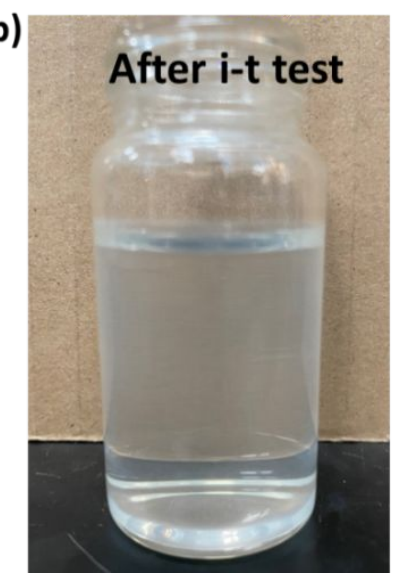

Figure S35. (a) Clarified saturated $\mathrm{Ca}(\mathrm{OH})_{2}$ solution; (b) The saturated $\mathrm{Ca}(\mathrm{OH})_{2}$ solution became turbid after introduced the used electrolyte, indicating the existed of $\mathrm{CO}_{3}{ }^{2-}$ in the electrolyte after i-t test for $2 \mathrm{~h}$. 

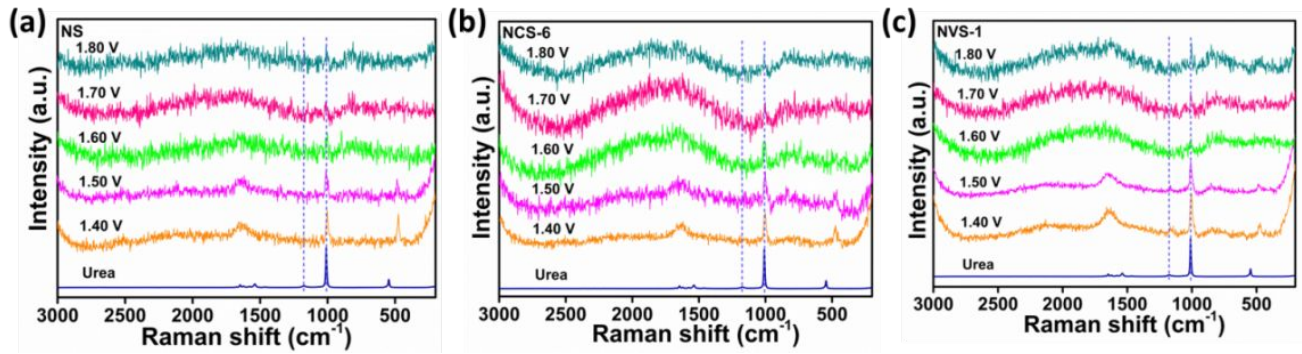

Figure S36. In-situ electrochemical Raman spectroscopy of UOR catalyzed by (a) NS; (b)

NCS-6; (c) NVS-1 at a various potential from $1.40 \mathrm{~V}$ to $1.80 \mathrm{~V}$ (vs. RHE).
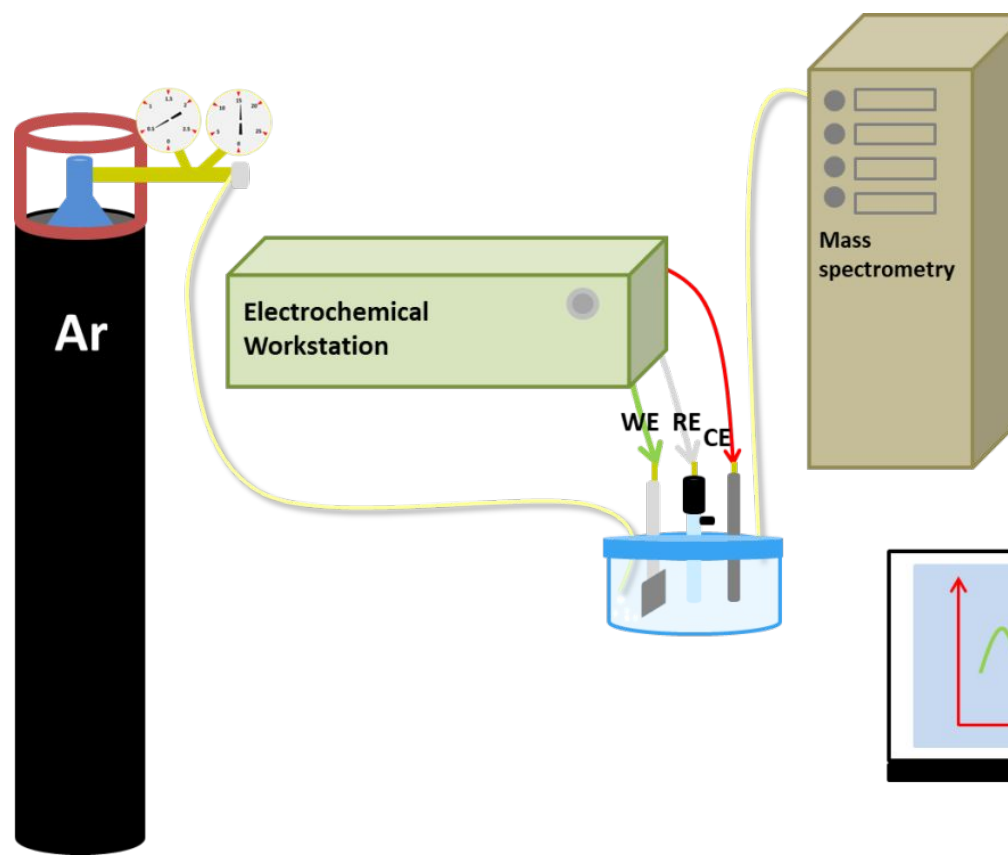

Figure S37. Schematic diagram of in-situ electrochemical mass spectrometry isotope tracing experiment. 

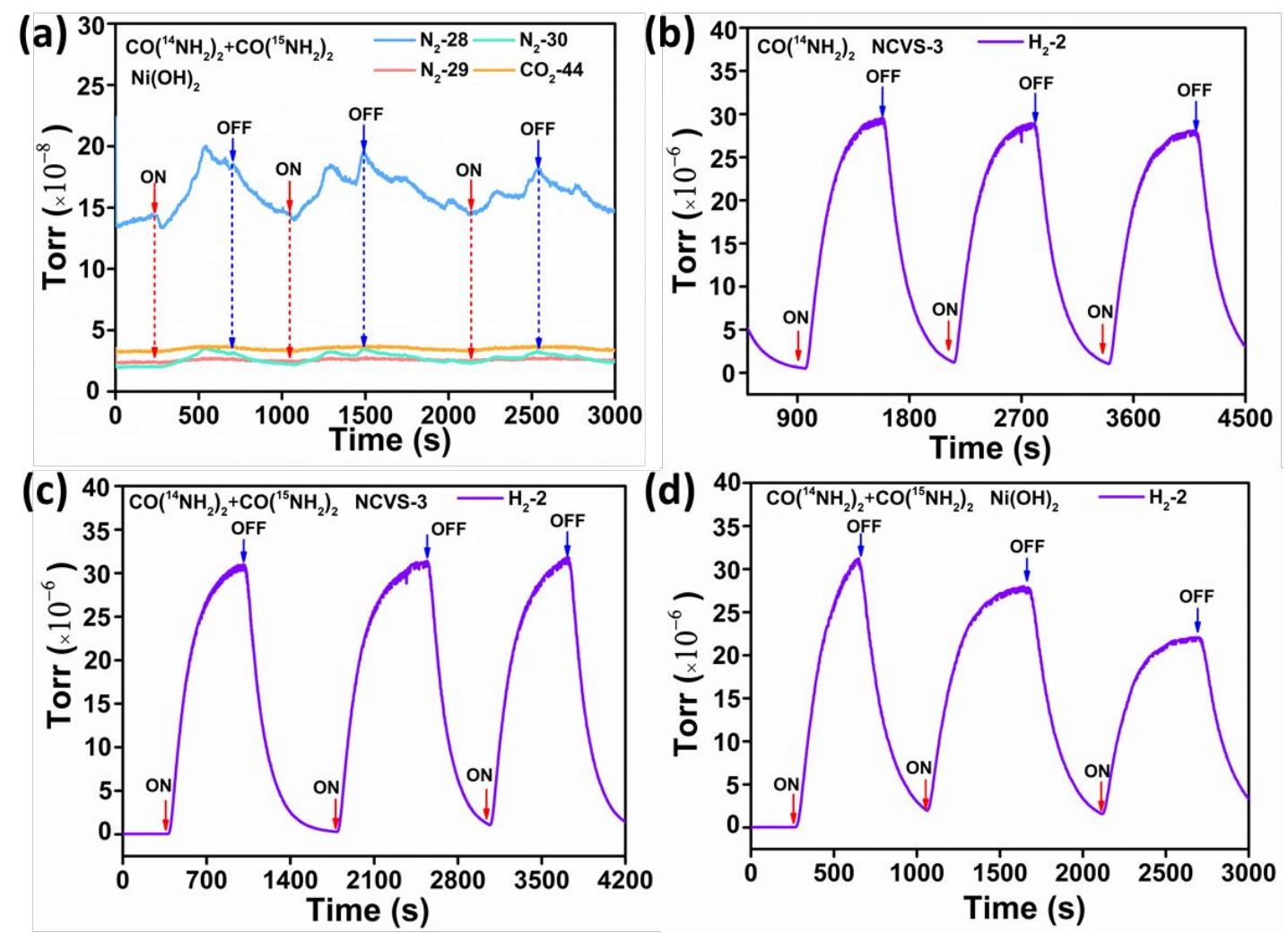

Figure S38. (a) In situ electrochemical mass spectrometry isotope tracing experiment for periodic measurement of the UOR in $1 \mathrm{M} \mathrm{KOH}$ and $0.33 \mathrm{M}$ urea $\left(\mathrm{CO}\left({ }^{14} \mathrm{NH}_{2}\right)_{2}\right.$ : $\left.\mathrm{CO}\left({ }^{15} \mathrm{NH}_{2}\right)_{2}=4: 1\right)$ under the catalysis of $\mathrm{Ni}(\mathrm{OH})_{2}$; The content of $\mathrm{H}_{2}$ under the catalysis of NCVS-3 in the electrolyte of (b) $1 \mathrm{M} \mathrm{KOH}+0.33 \mathrm{M}$ urea $\left(\mathrm{CO}\left({ }^{14} \mathrm{NH}_{2}\right)_{2}\right) ;(\mathrm{c}) 1 \mathrm{M}$ $\mathrm{KOH}+0.33 \mathrm{M}$ urea $\left(\mathrm{CO}\left({ }^{14} \mathrm{NH}_{2}\right)_{2}+\mathrm{CO}\left({ }^{15} \mathrm{NH}_{2}\right)_{2}\right)$; (d) The content of $\mathrm{H}_{2}$ under the catalysis of $\mathrm{Ni}(\mathrm{OH})_{2}$ in the electrolyte of $1 \mathrm{M} \mathrm{KOH}+0.33 \mathrm{M}$ urea $\left(\mathrm{CO}\left({ }^{14} \mathrm{NH}_{2}\right)_{2}+\mathrm{CO}\left({ }^{15} \mathrm{NH}_{2}\right)_{2}\right)$. 

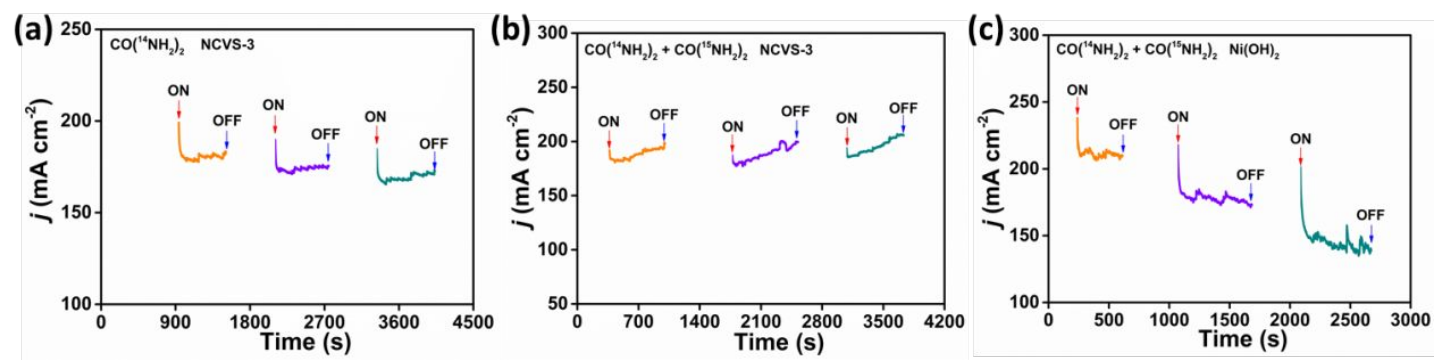

Figure S39. The i-t curves of NCVS-3 in (a) $1 \mathrm{M} \mathrm{KOH}$ and $0.33 \mathrm{M}$ urea $\left(\mathrm{CO}\left({ }^{14} \mathrm{NH}_{2}\right)_{2}\right)$; (b)

$1 \mathrm{M} \mathrm{KOH}$ and $0.33 \mathrm{M}$ urea $\left(\mathrm{CO}\left({ }^{14} \mathrm{NH}_{2}\right)_{2}+\mathrm{CO}\left({ }^{15} \mathrm{NH}_{2}\right)_{2}\right)$; (c) The i-t curves of $\mathrm{Ni}(\mathrm{OH})_{2}$ in 1 $\mathrm{M} \mathrm{KOH}$ and $0.33 \mathrm{M}$ urea $\left(\mathrm{CO}\left({ }^{14} \mathrm{NH}_{2}\right)_{2}+\mathrm{CO}\left({ }^{15} \mathrm{NH}_{2}\right)_{2}\right)$.
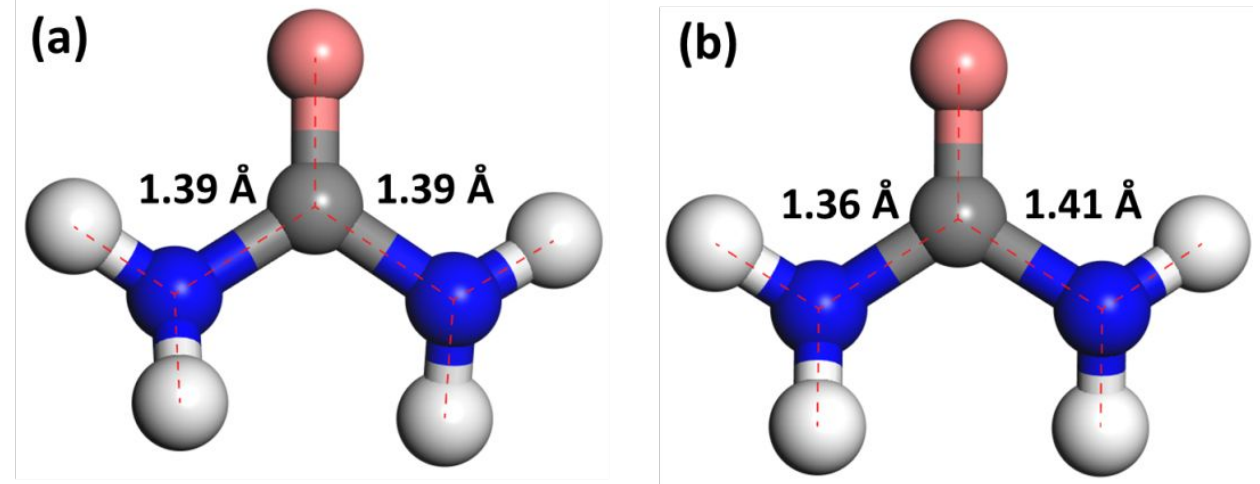

Figure S40 (a) Length of C-N bond in urea molecule; (b) Length of C-N bond in urea adsorbed on NCVS surface 


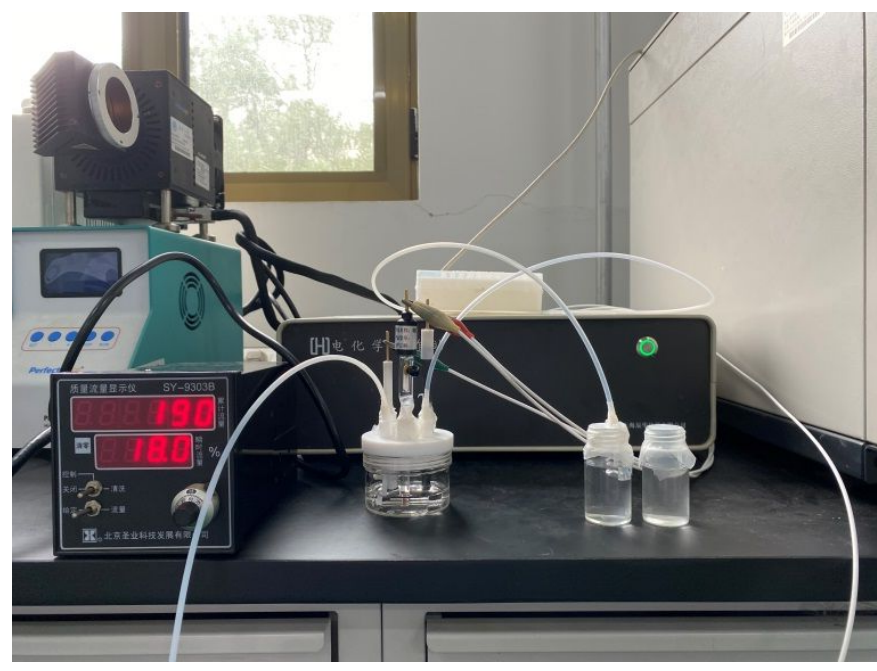

Figure S41. Carbonate decomposition experiment.

(a)

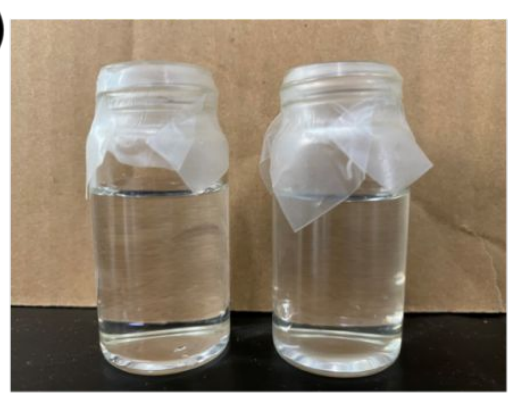

(c)

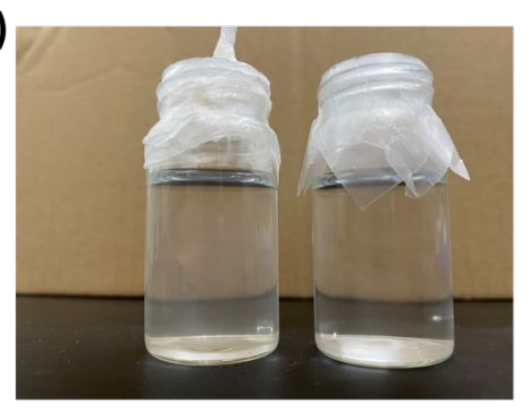

(b)

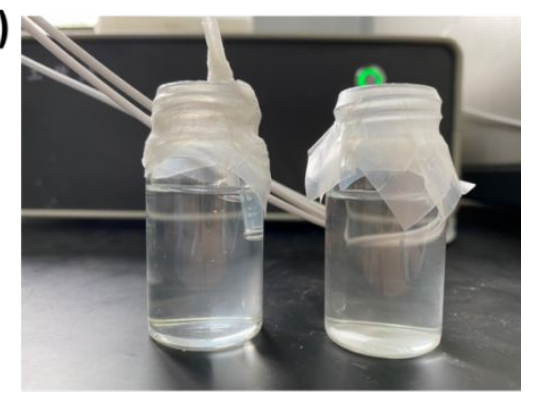

(d)

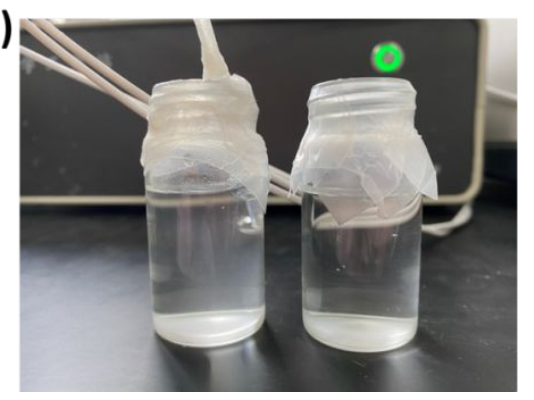

Figure S42. (a) Offline and (b) in-situ clarified saturated $\mathrm{Ca}(\mathrm{OH})_{2}$ solution before $\mathrm{K}_{2} \mathrm{CO}_{3}$ electrolysis test (left: test sample; right: control sample); (c) Offline and (d) in-situ saturated $\mathrm{Ca}(\mathrm{OH})_{2}$ solution after $\mathrm{K}_{2} \mathrm{CO}_{3}$ electrolysis test (left: test sample; right: control sample). 
Table S1. Ni $2 p_{3 / 2}$ XPS spectra peak data of NS, NCS-6, NVS-1 and NCVS-3 as well as the peak data of NVS-1 and NCVS-3 after i-t test of UOR for $10 \mathrm{~h}$.

\begin{tabular}{ccccc}
\hline Sample & \multicolumn{3}{c}{ Ni 2 $\mathbf{p}_{\mathbf{3} / \mathbf{2}}$} \\
NS & 853.3 & 855.6 & 858.1 & 860.9 \\
NCS-6 & 853.7 & 856.2 & 858.6 & 861.1 \\
NVS-1 & 854.1 & 856.6 & 859.1 & 862.0 \\
NCVS-3 & 853.8 & 856.3 & 858.4 & 861.5 \\
$\begin{array}{c}\text { NVS-1 } \\
\text { After 10h i-t } \\
\text { NCVS-3 }\end{array}$ & 855.3 & 856.0 & 856.9 & 861.7 \\
After 10h i-t & 854.9 & 855.7 & 856.7 & 861.4 \\
\hline
\end{tabular}

Table S2. Co $2 \mathrm{p}_{3 / 2}$ XPS spectra peak data of CS, NCS-6 and NCVS-3 as well as the peak data of NCVS-3 after i-t test of UOR for $10 \mathrm{~h}$.

\begin{tabular}{ccccc}
\hline Sample & \multicolumn{4}{c}{ Co 2 $\mathbf{p}_{\mathbf{3} / \mathbf{2}}$} \\
\hline CS & & 781.9 & 783.4 & 787.0 \\
NCS-6 & 777.8 & 780.1 & 784.3 & \\
NCVS-3 & 778.2 & 780.7 & 784.0 \\
$\begin{array}{c}\text { NCVS-3 } \\
\text { After 10h i-t }\end{array}$ & 779.8 & 781.9 & 786.3 \\
\hline
\end{tabular}


Table S3. V 2 $p_{3 / 2}$ XPS spectra peak data of VS, NVS-1 and NCVS-3 as well as the peak data of NVS-1 and NCVS-3 after i-t test of UOR for $10 \mathrm{~h}$.

\begin{tabular}{cccc}
\hline Sample & & $\mathbf{V ~ 2 \mathbf { p } _ { \mathbf { 3 } / \mathbf { 2 } }}$ \\
\hline VS & 516.8 & 517.8 \\
NVS-1 & 514.9 & 516.6 & 518.1 \\
NCVS-3 & 514.0 & 515.7 & 517.0 \\
$\begin{array}{c}\text { NVS-1 } \\
\text { After 12h i-t } \\
\text { NCVS-3 }\end{array}$ & 512.9 & 515.8 & 518.4 \\
After 12h i-t & 512.7 & 515.2 & 517.6 \\
\hline
\end{tabular}

Table S4. S 2p XPS spectra peak data of NS, NCS-6, NVS-1 and NCVS-3 as well as the peak data of NVS-1 and NCVS-3 after i-t test of UOR for $10 \mathrm{~h}$.

\begin{tabular}{|c|c|c|c|c|c|c|c|c|}
\hline \multirow{2}{*}{$\begin{array}{c}\text { Sample } \\
\text { NS }\end{array}$} & \multicolumn{4}{|c|}{ S 2p } & \multicolumn{3}{|c|}{$\mathrm{SO}_{3}{ }^{2-} / \mathrm{SO}_{4}{ }^{2-}$} & \\
\hline & 162.7 & 163.9 & & & 168.9 & 170.0 & & \\
\hline $\mathrm{CS}$ & 163.7 & & & & 168.9 & 169.3 & 170.0 & 170.5 \\
\hline VS & 163.4 & 163.7 & 164.0 & 164.7 & 168.6 & 170.0 & & \\
\hline NCS-6 & 162.4 & 163.6 & & & 168.8 & 170.0 & & \\
\hline NVS-1 & 162.5 & 163.7 & & & 168.9 & 170.0 & & \\
\hline NCVS-3 & 162.4 & 163.6 & & & 168.6 & 169.7 & & \\
\hline $\begin{array}{c}\text { NVS-1 } \\
\text { After 10h i-t }\end{array}$ & 162.8 & 165.0 & & & 168.6 & 169.4 & & \\
\hline $\begin{array}{c}\text { NCVS-3 } \\
\text { After 10h i-t }\end{array}$ & 161.6 & 164.5 & & & 168.5 & 169.7 & & \\
\hline
\end{tabular}


Table S5. O 1s XPS spectra peak data of NS, NCS-6, NVS-1 and NCVS-3 as well as the peak data of NVS-1 and NCVS-3 after i-t test of UOR for $10 \mathrm{~h}$.

\begin{tabular}{ccccc}
\hline Sample & & \multicolumn{3}{c}{ O 1s } \\
\hline NS & 531.5 & 532.1 & 532.7 & 533.5 \\
CS & 532.0 & 532.5 & 533.0 & 533.9 \\
VS & 530.4 & 530.9 & 531.6 & \\
NCS-6 & 531.6 & 532.2 & 532.9 & 533.6 \\
NVS-1 & 531.4 & 532.1 & 532.8 & 533.6 \\
NCVS-3 & 532.0 & 532.6 & 533.3 & 534.2 \\
$\quad$ NVS-1 & 530.9 & 531.5 & 532.1 & 532.8 \\
$\begin{array}{c}\text { After 12h i-t } \\
\text { NCVS-3 }\end{array}$ & 530.5 & 531.0 & 531.5 & 532.2 \\
After 12h i-t & & & & \\
\hline
\end{tabular}

Table S6. The concentration of V element in the electrolyte after i-t test of UOR for $10 \mathrm{~h}$.

Materials

NVS-1

NCVS-3
The concentration of $\mathrm{V}$ element $(\mu \mathrm{g} / \mathrm{L})$

17.05

14.29 
Table $\mathrm{S} 7$. The $\mathrm{R}_{\mathrm{s}}, \mathrm{R}_{\mathrm{p}}$ and $\mathrm{R}_{\mathrm{ct}}$ of NS, NCS-6, NVS-1 and NCVS-3 in UOR system.

\begin{tabular}{llll}
\hline Sample & $\mathbf{R}_{\mathrm{s}}$ & $\mathbf{R}_{\mathbf{p}}$ & $\mathbf{R}_{\mathbf{c t}}$ \\
\hline NCVS-1 & 1.20 & 300 & 298.80 \\
NCVS-2 & 1.41 & 56.77 & 55.40 \\
NCVS-3 & 1.27 & 6.26 & 5.00 \\
NCVS-4 & 1.33 & 10.75 & 9.40 \\
NCVS-5 & 1.41 & 8.67 & 7.30 \\
NCS-6 & 1.22 & 514.50 & 513.30 \\
NVS-1 & 1.24 & 38.96 & 37.70 \\
NS & 1.27 & 997.90 & 996.60 \\
\hline
\end{tabular}


Table S8. Comparison of urea electrooxidation performance.

\begin{tabular}{|c|c|c|c|c|}
\hline Materials & $\begin{array}{l}\text { E @ } 10 \mathrm{~mA} \mathrm{~cm} \text { ch }^{-2} \\
\text { (V vs. RHE) }\end{array}$ & $\begin{array}{l}j @ 1.5 \mathrm{~V}(\mathrm{vs} . \mathrm{RHE}) \\
\left(\mathrm{mA} \cdot \mathrm{cm}^{-2}\right)\end{array}$ & $\begin{array}{c}\text { Electrolyte } \\
\text { KOH / urea } \\
(\mathrm{M} / \mathrm{M})\end{array}$ & References \\
\hline NCS-6 & 1.33 & 73 & $1 / 0.33$ & This work \\
\hline NVS-1 & 1.35 & 74 & $1 / 0.33$ & This work \\
\hline NCVS-3 & 1.35 & 82 & $1 / 0.33$ & This work \\
\hline Ni-120 & 1.37 & 19 & $1 / 0.33$ & 6 \\
\hline $\mathrm{CoMn} / \mathrm{CoMn}_{2} \mathrm{O}_{4}$ & 1.31 & $>300$ & $1 / 0.5$ & 7 \\
\hline$N P-N i_{0.70} F_{0.30}$ & 1.43 & 60 & $1 / 0.33$ & 8 \\
\hline C-NiCo CHs & 1.17 & $>120$ & $1 / 0.33$ & 9 \\
\hline $\mathrm{Ni} / \mathrm{FeOOH}$ & 1.37 & $>200$ & $1 / 0.5$ & 10 \\
\hline NiIr-MOF & 1.32 & $>300$ & $1 / 0.5$ & 11 \\
\hline $\mathrm{NiSe}_{2}-\mathrm{NiO}$ & 1.33 & 150 & $1 / 0.33$ & 12 \\
\hline $\mathrm{NiO}-\mathrm{CFs}$ & 1.40 & 330 & $1 / 1$ & 13 \\
\hline Ni/Co oxide & 1.34 & 65 & $1 / 0.33$ & 14 \\
\hline $\mathrm{Ni}_{3} \mathrm{~N}-350$ & 1.34 & 300 & $1 / 0.5$ & 15 \\
\hline $\mathrm{Co}_{3} \mathrm{Mo}_{1} \mathrm{~S}$ & 1.31 & 110 & $1 / 0.5$ & 16 \\
\hline $\mathrm{NiFe} / \mathrm{N}-\mathrm{C}$ & 1.36 & $>250$ & $1 / 1$ & 17 \\
\hline$\beta-\mathrm{NiMoO}_{4}$ & 1.40 & 120 & $1 / 0.5$ & 18 \\
\hline$\alpha-\mathrm{NiMoO}_{4}$ & 1.44 & 25 & $1 / 0.5$ & 18 \\
\hline NiSnS & 1.36 & 76 & $1 / 0.33$ & 19 \\
\hline $\mathrm{NiMoO}_{3} \mathrm{~S}$ & 1.35 & 175 & $1 / 0.5$ & 20 \\
\hline
\end{tabular}




\begin{tabular}{|c|c|c|c|c|}
\hline h-NiWO 4 NPs/rGO & 1.35 & 150 & $1 / 0.33$ & 21 \\
\hline $\mathrm{Ru}-\mathrm{Co}_{2} \mathrm{P} / \mathrm{N}-\mathrm{C}$ & 1.30 & $>50$ & $1 / 0.5$ & 22 \\
\hline
\end{tabular}

Table S9. The Gibbs free energy calculated at the standard conditions and the simplified surface structures of the various reaction species along the reaction pathways of UOR on the surface of NS, NCS, NVS and NCVS.

\begin{tabular}{ccccc}
\hline \multirow{2}{*}{ Step/Samples } & \multicolumn{4}{c}{ Free Energy (eV) } \\
\cline { 2 - 5 } & NCVS & NVS & NCS & NS \\
\hline I & -0.36 & -0.32 & -0.33 & -0.27 \\
II & 3.32 & 4.60 & 4.31 & 5.25 \\
III & 2.67 & 3.94 & 4.05 & 4.86 \\
IV & 3.00 & 4.33 & 4.38 & 5.23 \\
VI & -1.31 & -0.015 & 0.107 & 0.9 \\
\hline
\end{tabular}

\section{References}

(1) Zhang, J.; Qian, J.; Ran, J.; Xi, P.; Yang, L.; Gao, D., Engineering Lower Coordination Atoms onto $\mathrm{NiO} / \mathrm{Co}_{3} \mathrm{O}_{4}$ Heterointerfaces for Boosting Oxygen Evolution Reactions. ACS Catal. 2020, 10, 12376-12384.

(2) Wang, W.; Zhu, Y.; Wen, Q.; Wang, Y.; Xia, J.; Li, C.; Chen, M.; Liu, Y.; Li, H.; Wu, H.; Zhai, T., Modulation of Molecular Spatial Distribution and Chemisorption with Perforated Nanosheets for Ethanol Electro-oxidation. Adv. Mater. 2019, 31, 1900528.

(3) Perdew, J. P.; Bruke, K.; Ernzerhof, M., Generalized Gradient Approximation Made Simple. Phy. Rev. Lett., 1996, 77, 3865.

(4) Grimme, S.; Antony, J.; Ehrlich, S.; Krieg, H., A consistent and accurate $a b$ initio parametrization of density functional dispersion correction (DFT-D) for the 94 elements H-Pu. J. Chem. Phys. 2010, 132, 154104.

(5) Rossmeisl, J.; Logadottir, A.; Nørskov, J., Electrolysis of water on (oxidized) 
metal surfaces. Chem. Phys. 2005, 319, 178-184.

(6) Tran, M. H.; Park, B. J.; Yoon, H. H., A highly active Ni-based anode material for urea electrocatalysis by a modified sol-gel method. J. Colloid Interface Sci. 2020, 578, 641-649.

(7) Wang, C.; Lu, H.; Mao, Z.; Yan, C.; Shen, G.; Wang, X., Bimetal Schottky Heterojunction Boosting Energy-Saving Hydrogen Production from Alkaline Water via Urea Electrocatalysis. Adv. Funct. Mater. 2020, 2000556.

(8) Cao, Z.; Zhou, T.; Ma, X.; Shen, Y.; Deng, Q.; Zhang, W.; Zhao, Y., Hydrogen Production from Urea Sewage on NiFe-Based Porous Electrocatalysts. ACS Sustain. Chem. Eng. 2020, 11007-11015.

(9) Khalafallah, D.; Ouyang, C.; Zhi, M.; Hong, Z.,Carbon Anchored Epitaxially Grown Nickel Cobalt-Based Carbonate Hydroxide for Urea Electrooxidation Reaction with a High Activity and Durability. Chem. Cat. Chem. 2020, 12, 1-13.

(10) Zhang, J. J.; Bao, W. W.; Li, M. Y.; Yang, C. M.;Zhang, N. N., Ultrafast formation of an $\mathrm{FeOOH}$ electrocatalyst on $\mathrm{Ni}$ for efficient alkaline water and urea oxidation. Chem. Commun. 2020, 56, 14713-14716.

(11) Xu, Y.; Chai, X.; Ren, T.; Yu, S.; Yu, H.; Wang, Z.; Li, X.; Wang, L.; Wang, H., Ir-Doped Ni-based metal-organic framework ultrathin nanosheets on $\mathrm{Ni}$ foam for enhanced urea electro-oxidation. Chem. Commun. 2020, 56, 2151-2154.

(12) Liu, Z.; Zhang, C.; Liu, H.; Feng, L., Efficient synergism of NiSe2 nanoparticle/ $\mathrm{NiO}$ nanosheet for energy-relevant water and urea electrocatalysis. Appl. Catal. B 2020, 276, 119165.

(13) Abd El-Lateef, H. M.; Khalaf, M. M.; Mohamed, I. M. A., An efficient and non-precious anode electrocatalyst of NiO-modified carbon nanofibers towards electrochemical urea oxidation in alkaline media. Ceram. Int. 2020, 46, 20376-20384.

(14) Wang, S.; Yang, X.; Liu, Z.; Yang, D.; Feng, L., Efficient nanointerfaces hybridization in Nickel/cobalt oxide nanorods bundle structure for urea electrolysis. Nanoscale 2020, 12, 10827-10833.

(15) Zhao, Z.; Zhao, J.; Wang, H.; Li, X.; Yang, L.; Zhao, Z.; Liu, X.; Liu, Y.; Liu, P.; Cai, Z., Porous flower-like nickel nitride as highly efficient bifunctional electrocatalysts for less energy-intensive hydrogen evolution and urea oxidation. Int. J. Hydrog. Energy 2020, 45, 14199-14207.

(16) Li, P.; Zhuang, Z.; Du, C.; Xiang, D.; Zheng, F.; Zhang, Z.; Fang, Z.; Guo, J.; Zhu, S.; Chen, W., Insights into the Mo-Doping Effect on the Electrocatalytic Performance of Hierarchical $\mathrm{Co}_{\mathrm{x}} \mathrm{Mo}_{\mathrm{y}} \mathrm{S}$ Nanosheet Arrays for Hydrogen Generation and Urea Oxidation. ACS Appl. Mater. Interfaces 2020, 12, 40194-40203.

(17) Zhang, J.; Xing, F.; Zhang, H.; Huang, Y., Ultrafine NiFe clusters anchored on $\mathrm{N}$-doped carbon as bifunctional electrocatalysts for efficient water and urea oxidation. Dalton Trans. 2020, 49, 13962-13969.

(18) Hu, K.; Jeong, S.; Elumalai, G.; Kukunuri, S.; Fujita, J.-i.; Ito, Y., Phase-Dependent Reactivity of Nickel Molybdates for Electrocatalytic Urea Oxidation. ACS Appl. Energy Mater. 2020, 3, 7535-7542.

(19) Ji, Z.; Liu, J.; Deng, Y.; Zhang, S.; Zhang, Z.; Du, P.; Zhao, Y.; Lu, X., Accurate synergy effect of $\mathrm{Ni}-\mathrm{Sn}$ dual active sites enhances electrocatalytic oxidation of urea 
for hydrogen evolution in alkaline medium. J. Mater. Chem. A 2020, 8, 14680-14689. (20) Han, W. K.; Li, X. P.; Lu, L. N.; Ouyang, T.; Xiao, K.; Liu, Z. Q., Partial S substitution activates $\mathrm{NiMoO}_{4}$ for efficient and stable electrocatalytic urea oxidation. Chem. Commun. 2020, 56, 11038-11041.

(21) Wang, Y.; Liu, G., Reduced graphene oxide supported nickel tungstate nano-composite electrocatalyst for anodic urea oxidation reaction in direct urea fuel cell. Int. J. Hydrog. Energy 2020, 45, 33500-33511.

(22) Xu, Y.; Ren, T.; Ren, K.; Yu, S.; Liu, M.; Wang, Z.; Li, X.; Wang, L.; Wang, H., Metal-organic frameworks-derived Ru-doped $\mathrm{Co}_{2} \mathrm{P} / \mathrm{N}$-doped carbon composite nanosheet arrays as bifunctional electrocatalysts for hydrogen evolution and urea oxidation. Chem. Eng. J. 2020, 408, 127308. 